\title{
Ground-State Gas-Phase Structures of Inorganic Molecules Predicted by Density Functional Theory Methods
}

\author{
Yury Minenkov*(i) and Luigi Cavallo*(1)
}

Physical Science and Engineering Division (PSE), KAUST Catalysis Center (KCC), King Abdullah University of Science and Technology (KAUST), 23955-6900 Thuwal, Saudi Arabia

\section{Supporting Information}

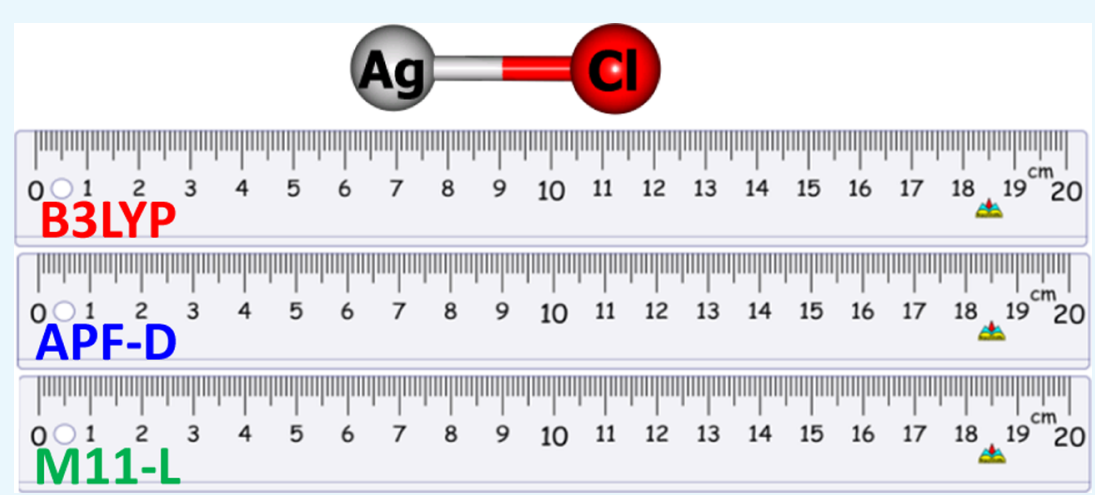

ABSTRACT: We tested a battery of density functional theory (DFT) methods ranging from generalized gradient approximation (GGA) via meta-GGA to hybrid meta-GGA schemes as well as Møller-Plesset perturbation theory of the second order and a single and double excitation coupled-cluster (CCSD) theory for their ability to reproduce accurate gas-phase structures of di- and triatomic molecules derived from microwave spectroscopy. We obtained the most accurate molecular structures using the hybrid and hybrid meta-GGA approximations with B3PW91, APF, TPSSh, mPW1PW91, PBE0, mPW1PBE, B972, and B98 functionals, resulting in lowest errors. We recommend using these methods to predict accurate three-dimensional structures of inorganic molecules when intramolecular dispersion interactions play an insignificant role. The structures that the CCSD method predicts are of similar quality although at considerably larger computational cost. The structures that GGA and meta-GGA schemes predict are less accurate with the largest absolute errors detected with BLYP and M11-L, suggesting that these methods should not be used if accurate three-dimensional molecular structures are required. Because of numerical problems related to the integration of the exchange-correlation part of the functional and large scattering of errors, most of the Minnesota models tested, particularly MN12-L, M11, M06-L, SOGGA11, and VSXC, are also not recommended for geometry optimization. When maintaining a low computational budget is essential, the nonseparable gradient functional N12 might work within an acceptable range of error. As expected, the DFT-D3 dispersion correction had a negligible effect on the internuclear distances when combined with the functionals tested on nonweakly bonded di- and triatomic inorganic molecules. By contrast, the dispersion correction for the APF-D functional has been found to shorten the bonds significantly, up to $0.064 \AA$ (AgI), in Ag halides, $\mathrm{BaO}$, $\mathrm{BaS}, \mathrm{BaF}, \mathrm{BaCl}, \mathrm{Cu}$ halides, and $\mathrm{Li}$ and $\mathrm{Na}$ halides and hydrides. These results do not agree well with very accurate structures derived from microwave spectroscopy; we therefore believe that the dispersion correction in the APF-D method should be reconsidered. Finally, we found that inaccurate structures can easily lead to errors of few $\mathrm{kcal} / \mathrm{mol}$ in single-point energies.

\section{INTRODUCTION}

The relative energies and other molecular properties of inorganic molecules are known to converge very slowly, often requiring expensive but rigorous and robust wave function theory (WFT) calculations in the complete basis set limit. ${ }^{1,2}$ By contrast, the molecular structures of these molecules are expected to converge more rapidly, ${ }^{1,2}$ and they can usually be obtained from relatively cheap density functional theory (DFT) methods with moderate basis sets of triple- $\zeta$ quality with polarization functions. To speed up routine quantum chemical calculations, Pople and co-workers ${ }^{3-7}$ proposed the so-called composite schemes in which sophisticated WFT methods are utilized only in a single-point (SP) fashion on the molecular structures optimized with much cheaper protocols, often based on DFT methods. Although the accuracy of SP energy evaluation methods is routinely tested to reproduce the thermochemistry of individual substances ${ }^{8-22}$ as well as chemical reactions, ${ }^{16,20,23-37}$ the systematic study of the quality of the molecular structures predicted by DFT is far less common. Selecting the particular method for geometry

Received: August 17, 2017

Accepted: November 1, 2017

Published: November 29, 2017 
Table 1. Experimental Internuclear Distances of Selected Diatomic Molecules Derived from Microwave Spectroscopy Measurements

\begin{tabular}{|c|c|c|}
\hline molecule $^{a}$ & $\mathrm{r}_{\mathrm{e}}(\AA)^{b}$ & refs \\
\hline $\operatorname{AgBr}\left({ }^{1} \Sigma^{+}\right)$ & $2.393109(2)\left({ }^{107} \mathrm{Ag}^{79} \mathrm{Br}\right)$ & 71 \\
\hline $\operatorname{AgCl}\left({ }^{1} \Sigma^{+}\right)$ & $2.2807916(6)\left({ }^{107} \mathrm{Ag}^{35} \mathrm{Cl}\right)$ & 72 \\
\hline $\operatorname{AgF}\left({ }^{1} \Sigma^{+}\right)$ & $1.983179(1)\left({ }^{107} \mathrm{Ag}^{19} \mathrm{~F}\right)$ & 73 \\
\hline $\operatorname{AgI}\left({ }^{1} \Sigma^{+}\right)$ & $2.5446165(12)\left({ }^{107} \mathrm{Ag}^{127} \mathrm{I}\right)$ & 71,74 \\
\hline $\operatorname{AlBr}\left({ }^{1} \Sigma^{+}\right)$ & $2.294859(3)\left({ }^{27} \mathrm{Al}^{79} \mathrm{Br}\right)$ & 75 \\
\hline $\mathrm{AlCl}\left({ }^{1} \Sigma^{+}\right)$ & $2.1301663(4)\left({ }^{27} \mathrm{Al}^{35} \mathrm{Cl}\right)$ & 75 \\
\hline $\operatorname{AlF}\left({ }^{1} \Sigma^{+}\right)$ & $1.6543688(4)\left({ }^{27} \mathrm{Al}^{19} \mathrm{~F}\right)$ & $76-78$ \\
\hline AlI $\left({ }^{1} \Sigma^{+}\right)$ & $2.5371027(3)\left({ }^{27} \mathrm{Al}^{127} \mathrm{I}\right)$ & 75 \\
\hline $\mathrm{BCl}\left({ }^{1} \Sigma^{+}\right)$ & $1.7194925(5)\left({ }^{11} \mathrm{~B}^{35} \mathrm{Cl}\right)$ & 79 \\
\hline $\mathrm{BF}\left({ }^{1} \Sigma^{+}\right)$ & $1.2625^{c}$ & 80 \\
\hline $\mathrm{BaO}\left({ }^{1} \Sigma^{+}\right)$ & $1.9396299(34)^{d}\left({ }^{138} \mathrm{Ba}^{16} \mathrm{O}\right)$ & 81,82 \\
\hline $\mathrm{BaS}\left({ }^{1} \Sigma^{+}\right)$ & $2.5073221(8)\left({ }^{138} \mathrm{Ba}^{32} \mathrm{~S}\right)$ & 83,84 \\
\hline $\mathrm{BrCl}\left({ }^{1} \Sigma^{+}\right)$ & $2.1360399(8)\left({ }^{79} \mathrm{Br}^{35} \mathrm{Cl}\right)^{d}$ & 85 \\
\hline $\operatorname{BrF}\left({ }^{1} \Sigma^{+}\right)$ & $1.7589200(18)\left({ }^{79} \mathrm{Br}^{19} \mathrm{~F}\right)$ & 85 \\
\hline $\mathrm{CO}\left({ }^{1} \Sigma^{+}\right)$ & $1.128229(1)\left({ }^{12} \mathrm{C}^{16} \mathrm{O}\right)^{d}$ & 86 \\
\hline $\operatorname{CS}\left({ }^{1} \Sigma^{+}\right)$ & $1.5348192(12)\left({ }^{12} \mathrm{C}^{32} \mathrm{~S}\right)^{c}$ & 87 \\
\hline $\operatorname{CSe}\left({ }^{1} \Sigma^{+}\right)$ & $1.67618(9)\left({ }^{12} \mathrm{C}^{80} \mathrm{Se}\right)^{c}$ & 88 \\
\hline $\mathrm{CaO}\left({ }^{1} \Sigma^{+}\right)$ & $1.8222034(3)\left({ }^{40} \mathrm{Ca}^{16} \mathrm{O}\right)$ & 89 \\
\hline $\mathrm{ClF}\left({ }^{1} \Sigma^{+}\right)$ & $1.6282718(5)\left({ }^{35} \mathrm{Cl}^{19} \mathrm{~F}\right)^{d}$ & 85 \\
\hline $\mathrm{CuBr}\left({ }^{1} \Sigma^{+}\right)$ & $2.173441(8)\left({ }^{63} \mathrm{Cu}^{79} \mathrm{Br}\right)^{d}$ & 90 \\
\hline $\mathrm{CuCl}\left({ }^{1} \Sigma^{+}\right)$ & $2.051192(1)\left({ }^{63} \mathrm{Cu}^{35} \mathrm{Cl}\right)^{d}$ & 91 \\
\hline $\operatorname{CuF}\left({ }^{1} \Sigma^{+}\right)$ & $1.744930(2)\left({ }^{63} \mathrm{Cu}^{19} \mathrm{~F}\right)$ & 73 \\
\hline $\mathrm{CuI}\left({ }^{1} \Sigma^{+}\right)$ & $2.3383236(15)\left({ }^{63} \mathrm{Cu}^{127} \mathrm{I}\right)^{d}$ & 92 \\
\hline $\mathrm{GaBr}\left({ }^{1} \Sigma^{+}\right)$ & $2.3524633(14)\left({ }^{69} \mathrm{Ga}^{79} \mathrm{Br}\right)$ & 93 \\
\hline $\mathrm{GaCl}\left({ }^{1} \Sigma^{+}\right)$ & $2.201690(3)\left({ }^{69} \mathrm{Ga}^{35} \mathrm{Cl}\right)$ & 94 \\
\hline $\mathrm{GaF}\left({ }^{1} \Sigma^{+}\right)$ & $1.7743691(9)\left({ }^{69} \mathrm{Ga}^{19} \mathrm{~F}\right)$ & 78 \\
\hline $\mathrm{GaI}\left({ }^{1} \Sigma^{+}\right)$ & $2.5746370(6)\left({ }^{69} \mathrm{Ga}^{127} \mathrm{I}\right)$ & 95 \\
\hline $\mathrm{GeO}\left({ }^{1} \Sigma^{+}\right)$ & $1.624647(2)\left({ }^{73} \mathrm{Ge}^{16} \mathrm{O}\right)$ & 96,97 \\
\hline $\operatorname{GeS}\left({ }^{1} \Sigma^{+}\right)$ & $2.0120863(1)\left({ }^{74} \mathrm{Ge}^{32} \mathrm{~S}\right)$ & 98 \\
\hline GeSe $\left({ }^{1} \Sigma^{+}\right)$ & $2.1346292(1)\left({ }^{74} \mathrm{Ge}^{80} \mathrm{Se}\right)$ & 98 \\
\hline $\operatorname{GeTe}\left({ }^{1} \Sigma^{+}\right)$ & $2.340165(12)\left({ }^{74} \mathrm{Ge}^{130} \mathrm{Te}\right)$ & 99 \\
\hline $\operatorname{HBr}\left({ }^{1} \Sigma^{+}\right)$ & $1.414435(3)\left({ }^{1} \mathrm{H}^{81} \mathrm{Br}\right)$ & 100 \\
\hline $\mathrm{HCl}\left({ }^{1} \Sigma^{+}\right)$ & $1.274552(6)\left({ }^{1} \mathrm{H}^{35} \mathrm{Cl}\right)$ & 101,102 \\
\hline $\mathrm{HF}\left({ }^{1} \Sigma^{+}\right)$ & $0.916809(27)\left({ }^{1} \mathrm{H}^{19} \mathrm{~F}\right)$ & $103-105$ \\
\hline $\mathrm{HI}\left({ }^{1} \Sigma^{+}\right)$ & $1.6090231(3)\left({ }^{1} \mathrm{H}^{127} \mathrm{I}\right)^{d}$ & 102,106 \\
\hline $\operatorname{IBr}\left({ }^{1} \Sigma^{+}\right)$ & $2.4689735(6)\left({ }^{127} \mathrm{I}^{79} \mathrm{Br}\right)^{d}$ & 85 \\
\hline $\mathrm{ICl}\left({ }^{1} \Sigma^{+}\right)$ & $2.320877(7)\left({ }^{127} \mathrm{I}^{35} \mathrm{Cl}\right)$ & 107 \\
\hline $\operatorname{IF}\left({ }^{1} \Sigma^{+}\right)$ & $1.909759(5)\left({ }^{127} \mathrm{I}^{19} \mathrm{~F}\right)$ & 108 \\
\hline $\operatorname{InBr}\left({ }^{1} \Sigma^{+}\right)$ & $2.5431804(55)\left({ }^{115} \mathrm{In}^{79} \mathrm{Br}\right)$ & 109 \\
\hline $\operatorname{InCl}\left({ }^{1} \Sigma^{+}\right)$ & $2.401168(2)\left({ }^{115} \mathrm{In}^{35} \mathrm{Cl}\right)$ & $110-112$ \\
\hline $\operatorname{InF}\left({ }^{1} \Sigma^{+}\right)$ & $1.9853964(9)\left({ }^{115} \operatorname{In}^{19} \mathrm{~F}\right)$ & 78 \\
\hline $\operatorname{InI}\left({ }^{1} \Sigma^{+}\right)$ & $2.753639(54)\left({ }^{115} \operatorname{In}^{127} \mathrm{I}\right)$ & 113 \\
\hline $\operatorname{LiBr}\left({ }^{1} \Sigma^{+}\right)$ & $2.170428(4)\left({ }^{6} \mathrm{Li}^{79} \mathrm{Br}\right)$ & 114,115 \\
\hline $\mathrm{LiCl}\left({ }^{1} \Sigma^{+}\right)$ & $2.0206676(4)\left({ }^{6} \mathrm{Li}^{35} \mathrm{Cl}\right)$ & 116,117 \\
\hline
\end{tabular}

\begin{tabular}{|c|c|c|}
\hline molecule $^{a}$ & $\mathrm{r}_{\mathrm{e}}(\AA)^{b}$ & refs \\
\hline $\operatorname{LiF}\left({ }^{1} \Sigma^{+}\right)$ & $1.5638601(3)\left({ }^{6} \mathrm{Li}^{19} \mathrm{~F}\right)$ & 116,118 \\
\hline $\mathrm{LiH}\left({ }^{1} \Sigma^{+}\right)$ & $1.5949131(8)\left({ }^{6} \mathrm{Li}^{1} \mathrm{H}\right)^{d}$ & 119 \\
\hline $\operatorname{LiI}\left({ }^{1} \Sigma^{+}\right)$ & $2.391907(14)\left({ }^{6} \mathrm{Li}^{127} \mathrm{I}\right)$ & 120 \\
\hline $\mathrm{MgO}\left({ }^{1} \Sigma^{+}\right)$ & $1.7483805(1)\left({ }^{24} \mathrm{Mg}^{16} \mathrm{O}\right)$ & 121 \\
\hline $\mathrm{NaBr}\left({ }^{1} \Sigma^{+}\right)$ & $2.5020379(12)\left({ }^{23} \mathrm{Na}^{79} \mathrm{Br}\right)$ & 117,122 \\
\hline $\mathrm{NaCl}\left({ }^{1} \Sigma^{+}\right)$ & $2.360795(2)\left({ }^{23} \mathrm{Na}^{35} \mathrm{Cl}\right)$ & 123,124 \\
\hline $\mathrm{NaF}\left({ }^{1} \Sigma^{+}\right)$ & $1.9259465(3)\left({ }^{23} \mathrm{Na}^{19} \mathrm{~F}\right)$ & 125,126 \\
\hline $\mathrm{NaH}\left({ }^{1} \Sigma^{+}\right)$ & $1.88652(9)\left({ }^{23} \mathrm{Na}^{1} \mathrm{H}\right)^{d}$ & 127,128 \\
\hline $\mathrm{NaI}\left({ }^{1} \Sigma^{+}\right)$ & $2.711452(2)\left({ }^{23} \mathrm{Na}^{127} \mathrm{I}\right)$ & 117,122 \\
\hline $\operatorname{PN}\left({ }^{1} \Sigma^{+}\right)$ & $1.4908663(5)\left({ }^{31} \mathrm{P}^{14} \mathrm{~N}\right)$ & $129-131$ \\
\hline $\mathrm{PbO}\left({ }^{1} \Sigma^{+}\right)$ & $1.9218134(17)\left({ }^{207} \mathrm{~Pb}^{16} \mathrm{O}\right)$ & 132,133 \\
\hline $\operatorname{PbS}\left({ }^{1} \Sigma^{+}\right)$ & $2.2868628(12)\left({ }^{207} \mathrm{~Pb}^{32} \mathrm{~S}\right)$ & 133,134 \\
\hline $\mathrm{PbSe}\left({ }^{1} \Sigma^{+}\right)$ & $2.4022353(22)\left({ }^{208} \mathrm{~Pb}^{80} \mathrm{Se}\right)$ & 99,135 \\
\hline $\operatorname{PbTe}\left({ }^{1} \Sigma^{+}\right)$ & $2.594975(4)\left({ }^{208} \mathrm{~Pb}^{130} \mathrm{Te}\right)$ & 99,136 \\
\hline $\mathrm{SiO}\left({ }^{1} \Sigma^{+}\right)$ & $1.5097375(2)\left({ }^{28} \mathrm{Si}^{16} \mathrm{O}\right)$ & 97,137 \\
\hline $\operatorname{SiS}\left({ }^{1} \Sigma^{+}\right)$ & $1.9293212(2)\left({ }^{28} \mathrm{Si}^{32} \mathrm{~S}\right)$ & 138,139 \\
\hline SiSe $\left({ }^{1} \Sigma^{+}\right)$ & $2.058327(4)\left({ }^{28} \mathrm{Si}^{80} \mathrm{Se}\right)$ & 140,141 \\
\hline $\mathrm{SnO}\left({ }^{1} \Sigma^{+}\right)$ & $1.8325054(20)\left({ }^{120} \mathrm{Sn}^{16} \mathrm{O}\right)$ & 133,142 \\
\hline $\operatorname{SnS}\left({ }^{1} \Sigma^{+}\right)$ & $2.2090267(3)\left({ }^{120} \mathrm{Sn}^{32} \mathrm{~S}\right)$ & 133,143 \\
\hline SnSe $\left({ }^{1} \Sigma^{+}\right)$ & $2.325601(3)\left({ }^{120} \mathrm{Sn}^{80} \mathrm{Se}\right)$ & 144,145 \\
\hline $\operatorname{SnTe}\left({ }^{1} \Sigma^{+}\right)$ & $2.522814(1)\left({ }^{120} \mathrm{Sn}^{130} \mathrm{Te}\right)$ & 145,146 \\
\hline $\mathrm{SrO}\left({ }^{1} \Sigma^{+}\right)$ & $1.919849(1)\left({ }^{88} \mathrm{Sr}^{16} \mathrm{O}\right)^{c}$ & 82 \\
\hline $\operatorname{TlBr}\left({ }^{1} \Sigma^{+}\right)$ & $2.618184(11)\left({ }^{205} \mathrm{Tl}^{79} \mathrm{Br}\right)$ & 147,148 \\
\hline $\operatorname{TlCl}\left({ }^{1} \Sigma^{+}\right)$ & $2.4848260(4)\left({ }^{205} \mathrm{Tl}^{35} \mathrm{Cl}\right)$ & 149,150 \\
\hline $\operatorname{TlF}\left({ }^{1} \Sigma^{+}\right)$ & $2.0844377(1)\left({ }^{205} \mathrm{Tl}^{19} \mathrm{~F}\right)$ & 151,152 \\
\hline $\operatorname{TlI}\left({ }^{1} \Sigma^{+}\right)$ & $2.813676(10)\left({ }^{205} \mathrm{Tl}^{127} \mathrm{I}\right)$ & 147,148 \\
\hline $\mathrm{BaCl}\left({ }^{2} \Sigma^{+}\right)$ & $2.6827325(5)\left({ }^{138} \mathrm{Ba}^{35} \mathrm{Cl}\right)$ & 153 \\
\hline $\mathrm{BaF}\left({ }^{2} \Sigma^{+}\right)$ & $2.1592708(6)\left({ }^{138} \mathrm{Ba}^{19} \mathrm{~F}\right)$ & 154 \\
\hline $\mathrm{CN}\left({ }^{2} \Sigma^{+}\right)$ & $1.171807(20)\left({ }^{12} \mathrm{C}^{14} \mathrm{~N}\right)^{c}$ & 155 \\
\hline $\mathrm{CaBr}\left({ }^{2} \Sigma^{+}\right)$ & $2.5935838(4)\left({ }^{40} \mathrm{Ca}{ }^{79} \mathrm{Br}\right)$ & 156 \\
\hline $\mathrm{CaCl}\left({ }^{2} \Sigma^{+}\right)$ & $2.4367580(4)\left({ }^{40} \mathrm{Ca}^{35} \mathrm{Cl}\right)$ & 156 \\
\hline $\operatorname{SrCl}\left({ }^{2} \Sigma^{+}\right)$ & $2.575854(1)\left({ }^{88} \mathrm{Sr}^{35} \mathrm{Cl}\right)$ & 157 \\
\hline $\operatorname{SrF}\left({ }^{2} \Sigma^{+}\right)$ & $2.075366(1)\left({ }^{88} \mathrm{Sr}^{19} \mathrm{~F}\right)$ & 157 \\
\hline $\operatorname{BiBr}\left({ }^{3} \Sigma^{+}\right)$ & $2.6095031(24)\left({ }^{209} \mathrm{Bi}^{79} \mathrm{Br}\right)$ & 158 \\
\hline $\mathrm{BiCl}\left({ }^{3} \Sigma^{+}\right)$ & $2.4715223(8)\left({ }^{209} \mathrm{Bi}^{35} \mathrm{Cl}\right)$ & 159 \\
\hline $\operatorname{BiF}\left({ }^{3} \Sigma^{+}\right)$ & $2.0515431(3)\left({ }^{209} \mathrm{Bi}^{19} \mathrm{~F}\right)$ & 160 \\
\hline BiI $\left({ }^{3} \Sigma^{+}\right)$ & $2.8005010(3)\left({ }^{209} \mathrm{Bi}^{127} \mathrm{I}\right)$ & 161 \\
\hline SO $\left({ }^{3} \Sigma^{+}\right)$ & $1.4809899(13)\left({ }^{32} \mathrm{~S}^{16} \mathrm{O}\right)^{d}$ & 162 \\
\hline $\mathrm{SeO}\left({ }^{3} \Sigma^{+}\right)$ & $1.6394792(18)\left({ }^{78} \mathrm{Se}^{16} \mathrm{O}\right)^{d}$ & 163 \\
\hline
\end{tabular}

${ }^{a}$ Ground-state molecular term. ${ }^{b}$ Calculated as $\mathrm{r}_{\mathrm{e}}=[505379.006(51) /$ $\left.\mu_{\mathrm{r}} Y_{01}\right]^{1 / 2}$ as in the NIST database unless otherwise noted. ${ }^{c}$ Taken from the original work. ${ }^{d}$ Calculated as $\mathrm{r}_{\mathrm{e}}=\left[505379.006(51) / \mu_{\mathrm{r}} B_{\mathrm{e}}\right]^{1 / 2}$ as in the NIST database.

optimization and estimating the potential inaccuracies arising from such a choice remain difficult.

An analysis of studies ${ }^{27,37-56}$ testing the accuracy of DFT molecular structures suggests that, first, hybrid-, double-hybrid-, meta-, and hybrid-meta-generalized gradient approximation (GGA) functionals generally provide better structures than classical GGA schemes; and, second, dispersion-corrected DFT functionals usually outperform their standard counterparts if significant noncovalent intra- or intermolecular interactions can be found in the system. It is impossible to identify the method that results in the best molecular structures because the performance of individual functionals is not homogeneous. Often, a functional performing well for one class of compounds provides moderate or even quite poor accuracy for another group of compounds. Even if the above-mentioned studies can provide a rough idea for the most suitable protocol for a given chemical system, these studies often have at least one of the two following shortcomings. First, in many studies benchmarking the quality of three-dimensional molecular structures, the most recent DFT functionals are not included, which is not surprising, as many functionals appeared in the last decade and became available through the latest releases of quantum chemistry computer codes. Second, the referenced experimental structures quite often are from diffraction methods and cannot, strictly speaking, be directly compared with the calculated structures in a rigorous way. The molecular structures obtained from DFT or WFT methods correspond to the potential energy minimum. Often such structures are 
Table 2. Experimental Molecular Structures of Selected Triatomic Molecules Derived from Microwave Spectroscopy Measurements

\begin{tabular}{|c|c|c|c|c|c|}
\hline molecule $(\mathrm{ABC})^{a}$ & type & $\mathrm{r}_{\mathrm{AB}}(\AA)$ & $\mathrm{r}_{\mathrm{BC}}(\AA)$ & $\angle A B C^{b}(\operatorname{deg})$ & refs \\
\hline $\mathrm{BrNO}\left({ }^{1} \mathrm{~A}^{\prime}\right)$ & $\mathrm{r}_{\mathrm{s}}$ & $2.140(2)$ & $1.146(10)$ & $114.50(50)$ & 164 \\
\hline $\mathrm{ClCN}\left({ }^{1} \Sigma^{+}\right)$ & $\mathrm{r}_{\mathrm{e}}$ & $1.629(6)$ & $1.160(7)$ & 180 & 165 \\
\hline $\mathrm{CINO}\left({ }^{1} \mathrm{~A}^{\prime}\right)$ & $r_{s}$ & $1.975(5)$ & $1.139(12)$ & $113.3(6)$ & 166 \\
\hline $\mathrm{FCN}\left({ }^{1} \Sigma^{+}\right)$ & $r_{s}$ & $1.262(2)$ & $1.159(2)$ & 180 & 167 \\
\hline FNO $\left({ }^{1} A^{\prime}\right)$ & $\mathrm{r}_{\mathrm{s}}$ & $1.512(5)$ & $1.136(3)$ & $110.1(2)$ & 168 \\
\hline $\mathrm{GeF}_{2}\left({ }^{1} \mathrm{~A}_{1}\right)$ & $\mathrm{r}_{\mathrm{e}}$ & 1.7321 & 1.7321 & 97.148 & 169 \\
\hline $\mathrm{H}_{2} \mathrm{O}\left({ }^{1} \mathrm{~A}_{1}\right)$ & $r_{e}$ & $0.9587(1)$ & $0.9587(1)$ & $103.89(0.06)$ & 170 \\
\hline $\mathrm{H}_{2} \mathrm{~S}\left({ }^{1} \mathrm{~A}_{1}\right)$ & $r_{e}$ & 1.3356 & 1.3356 & 92.11 & 171,172 \\
\hline $\mathrm{H}_{2} \mathrm{Se}\left({ }^{1} \mathrm{~A}_{1}\right)$ & $\mathrm{r}_{\mathrm{e}}$ & $1.4605(30)$ & $1.4605(30)$ & $90.92(12)$ & 173 \\
\hline $\operatorname{HBS}\left({ }^{1} \Sigma^{+}\right)$ & $r_{s}$ & $1.1692(4)$ & $1.5995(4)$ & 180 & 174 \\
\hline $\mathrm{HCN}\left({ }^{1} \Sigma^{+}\right)$ & $\mathrm{r}_{\mathrm{e}}$ & $1.0655(5)$ & $1.15321(10)$ & 180 & 175 \\
\hline $\operatorname{HCP}\left({ }^{1} \Sigma^{+}\right)$ & $\mathrm{r}_{\mathrm{e}}$ & $1.0692(8)$ & $1.5398(2)$ & 180 & 176 \\
\hline $\operatorname{HNC}\left({ }^{1} \Sigma^{+}\right)$ & $\mathrm{r}_{\mathrm{s}}$ & $0.98607(9)$ & $1.17168(22)$ & 180 & 177,178 \\
\hline $\mathrm{NNO}\left({ }^{1} \Sigma^{+}\right)$ & $\mathrm{r}_{\mathrm{s}}$ & $1.1286(3)$ & $1.1876(3)$ & 180 & 179 \\
\hline $\operatorname{NSCl}\left({ }^{1} \mathrm{~A}^{\prime}\right)$ & $\mathrm{r}_{\mathrm{s}}$ & 1.450 & 2.161 & 117.7 & 180 \\
\hline $\mathrm{O}_{3}\left({ }^{1} \mathrm{~A}_{1}\right)$ & $r_{e}$ & $1.2717(2)$ & $1.2717(2)$ & 116.78 & 181 \\
\hline OCS $\left({ }^{1} \Sigma^{+}\right)$ & $\mathrm{r}_{\mathrm{e}}$ & $1.1543(10)$ & $1.5628(10)$ & 180 & 182 \\
\hline OCSe $\left({ }^{1} \Sigma^{+}\right)$ & $r_{e}$ & $1.1535(1)$ & $1.7098(1)$ & 180 & 183 \\
\hline $\mathrm{OF}_{2}\left({ }^{1} \mathrm{~A}_{1}\right)$ & $\mathrm{r}_{\mathrm{e}}$ & $1.4053(4)$ & $1.4053(4)$ & $103.07(06)$ & 184 \\
\hline $\mathrm{SO}_{2}\left({ }^{1} \mathrm{~A}_{1}\right)$ & $\mathrm{r}_{\mathrm{e}}$ & $1.43076(13)$ & $1.43076(13)$ & $119.33(1)$ & 185 \\
\hline $\mathrm{SeO}_{2}\left({ }^{1} \mathrm{~A}_{1}\right)$ & $\mathrm{r}_{\mathrm{e}}$ & $1.6076(6)$ & $1.6076(6)$ & 113.83 & 186 \\
\hline $\mathrm{SiF}_{2}\left({ }^{1} \mathrm{~A}_{1}\right)$ & $\mathrm{r}_{\mathrm{e}}$ & $1.5901(1)$ & $1.5901(1)$ & $100.77(2)$ & 187 \\
\hline $\mathrm{ClO}_{2}\left({ }^{2} \mathrm{~B}_{1}\right)$ & $\mathrm{r}_{\mathrm{s}}$ & 1.471 & 1.471 & 117.5 & $188-190$ \\
\hline $\mathrm{NO}_{2}\left({ }^{2} \mathrm{~A}_{1}\right)$ & $\mathrm{r}_{\mathrm{e}}$ & $1.1945(5)$ & $1.1945(5)$ & $133.85(10)$ & 191 \\
\hline
\end{tabular}

${ }^{a}$ Ground-state molecular term. ${ }^{b}$ For comparisons with $r_{e}$ structures from DFT and WFT methods, we modify the structural description with the two distances and a bend angle in favor of three distances.

abbreviated as $r_{e}$ (equilibrium three-dimensional structure). Unfortunately, there are no experimental methods that provide direct access to the equilibrium structure. ${ }^{57}$ Thus, the result of a gas-phase electron diffraction (GED) experiment is the threedimensional molecular structure averaged over all molecular vibrations at a certain temperature, $r_{a}$. Another popular diffraction method in chemistry, X-ray analysis, results in structures of molecules that, in addition to being averaged over vibrations and librations, are also influenced by effects arising from crystal-packing forces. Clearly both kinds of structures cannot be directly compared to equilibrium structures, $r_{e}$, obtained from quantum chemistry methods. Several approximations exist to modify the experimental structures from diffraction methods to make them more comparable to their $r_{e}$ counterparts, for example, through inclusions of the effects from vibrations (e.g., $\mathbf{r}_{\mathrm{h} 1}, \mathrm{r}_{\alpha}$, etc. in GED) ${ }^{58-62}$ However, the accuracy of such approximations remains open to debate.

Here, we seek to contribute to existing studies that benchmark three-dimensional molecular structures in two ways. First, along with the standard well-tested functionals, including $\mathrm{PBE}^{63,64}$ and B3LYP, ${ }^{65-68}$ we also include the most recent functionals, in particular, the latest methods from the Minnesota group on which many fewer molecular geometry validation studies are available in the literature. As reference structures, we use molecular structures from gas-phase microwave spectroscopy.

\section{COMPUTATIONAL DETAILS}

2.1. Benchmark Set. We extracted the reference molecular structures from microwave spectroscopy measurements from the National Institute of Standards and Technology (NIST) Diatomic $^{69}$ and Triatomic ${ }^{70}$ Spectral Databases. We selected molecules for which only the most reliable measurements were available. They are listed in Tables 1 and 2 . In particular, we include only diatomic molecules for which $r_{e}$ molecular structures are provided in the dataset. Similarly, we include only triatomic molecules for which $r_{e}$ or $r_{s}$ (distances obtained through isotopic substitution experiments $)^{57}$ structures are available in the dataset. We give preference to $r_{e}$ if both $r_{e}$ and $r_{s}$ (isotopic substitution) structures are available.

2.2. Geometry Optimizations. We performed all geometry optimizations with the most popular DFT functionals listed in Table 3 as implemented in the Gaussian $09^{192}$ suite of programs. We adopted the default values for the self-consistentfield and geometry optimization convergence criteria. We performed numerical integration of the exchange-correlation (XC) terms using the tighter-than-default "ultrafine" option (pruned, 99 radial shells and 590 angular points per shell) to eliminate the potential numerical noise in the energy derivatives. We applied Grimme's D3(BJ) ${ }^{193}$ dispersion correction to PBE, TPSS, BP86, B3PW91, B3LYP, BLYP, BPBE, BMK, CAM-B3LYP, LC- $\omega$ PBE, and PBE0 to arrive at the corresponding DFT-D3(BJ) methods and to account for the possible influence of the dispersion interactions not (or only partly) covered by the standard functionals. However, because in practically all cases we observed only insignificant differences in internuclear distances of only ca. $0.001 \AA$ (or less) upon inclusion of the dispersion correction, we discuss only the dispersion-uncorrected results for the abovementioned functionals. In addition to DFT functionals, we also optimized all structures with Møller-Plesset perturbation theory of the second order (MP2) and single and double excitation coupled-cluster (CCSD) methods for which analytical electronic energy first derivatives (gradients) are 
Table 3. Summary of the Methods Used in the Present Work to Optimize the Molecular Structures

\begin{tabular}{|c|c|c|}
\hline method & type $^{a}$ & refs \\
\hline PBE & GGA & 63,64 \\
\hline BP86 & GGA & 65,212 \\
\hline BLYP & GGA & 65,66 \\
\hline $\mathrm{BPBE}$ & GGA & 63,65 \\
\hline НСТН/407 & GGA & $213-215$ \\
\hline B97-D & $\mathrm{GGA}+\mathrm{D}$ & 216 \\
\hline B97-D3 & $\mathrm{GGA}+\mathrm{D}$ & 216,217 \\
\hline SOGGA11 & GGA & 218 \\
\hline $\mathrm{N} 12$ & NGA & 219 \\
\hline OLYP & GGA & $66,220-222$ \\
\hline TPSS & mGGA & 223 \\
\hline VSXC & mGGA & 224 \\
\hline M06-L & mGGA & 225 \\
\hline M11-L & mGGA & 226 \\
\hline MN12-L & mNGA & 227 \\
\hline B3PW91 & GH-GGA & $65,68,228-232$ \\
\hline B3LYP & GH-GGA & 65,68 \\
\hline mPW1PW91 & GH-GGA & 233 \\
\hline SOGGA11-X & GH-GGA & 234 \\
\hline PBE0 & GH-GGA & 63,64 \\
\hline mPW1LYP & GH-GGA & $66,222,233$ \\
\hline mPW1PBE & GH-GGA & $63,64,233$ \\
\hline X3LYP & GH-GGA & $66,222,235$ \\
\hline B971 & GH-GGA & 213 \\
\hline B972 & GH-GGA & 236 \\
\hline B98 & GH-GGA & 237,238 \\
\hline B1LYP & GH-GGA & 239 \\
\hline $\mathrm{APF}$ & GH-GGA & 240 \\
\hline APF-D & GH-GGA+D & 240 \\
\hline $\mathrm{LC}-\omega \mathrm{PBE}$ & RSH-GGA & 241 \\
\hline CAM-B3LYP & RSH-GGA & 242 \\
\hline N12-SX & RSH-GGA & 243 \\
\hline$\omega \mathrm{B} 97 \mathrm{X}-\mathrm{D}$ & RSH-GGA+D & 244 \\
\hline BMK & GH-mGGA & 245 \\
\hline TPSSh & GH-mGGA & 223,246 \\
\hline M06 & GH-mGGA & 247 \\
\hline M11 & RSH-mGGA & 248 \\
\hline MN12-SX & RSH-mGGA & 243 \\
\hline MP2 & WFT & 249 \\
\hline CCSD & WFT & $250-253$ \\
\hline
\end{tabular}

$a_{+} \mathrm{D}=$ functional corrected for dispersion interactions, NGA = nonseparable gradient approximation, mGGA = meta-GGA, mNGA = meta-NGA, GH = global hybrid, and $\mathrm{RSH}=$ range-separated hybrid.

available. In both WFT methods, we included all electrons in the correlation treatment as the core-valence and core-core correlation effects have been shown to be important for some inorganic species. $8,26,194-200$

We used the following triple- $\zeta$ correlation-consistent basis sets. We used Dunning's cc-pVTZ basis sets to describe hydrogen. ${ }^{201}$ We described lithium, sodium, and magnesium with Wilson et al.'s all-electron (AE) correlation-consistent core-valence cc-pwCVTZ basis sets. ${ }^{202}$ We used Dunning and Peterson's AE correlation-consistent core-valence cc-pwCVTZ basis sets to describe boron, carbon, nitrogen, oxygen, fluorine, aluminum, silicon, phosphorus, sulfur, chlorine, and argon. ${ }^{203}$ We used Li et al.'s pseudopotential-based correlation-consistent core-valence cc-pwCVTZ-PP basis sets to describe calcium, strontium, and barium. ${ }^{204}$ The 10 core electrons of Ca, the 28 core electrons of $\mathrm{Sr}$, and the 46 core electrons of $\mathrm{Ba}$ were described with Stuttgart-type fully relativistic effective core potentials of Schwerdtfeger and co-workers. ${ }^{205}$ Copper and silver were described with the pseudopotential-based correlation-consistent core-valence cc-pwCVTZ-PP basis sets of Peterson and Puzzarini. ${ }^{206}$ The 10 core electrons of $\mathrm{Cu}$ and the 28 core electrons of Ag were described with Stuttgart-type fully relativistic effective core potentials of Stoll and coworkers. $^{207}$ Gallium, germanium, selenium, bromine indium, tin, tellurium, iodine, thallium, lead, and bismuth were described with the pseudopotential-based correlation-consistent core-valence cc-pwCVTZ-PP basis set of Peterson and Yousaf. $^{208}$ The 10 core electrons of $\mathrm{Ga}, \mathrm{Ge}, \mathrm{Se}$, and $\mathrm{Br}$, the 28 core electrons of In, $\mathrm{Sn}, \mathrm{Te}$, and I, and the 60 core electrons of $\mathrm{Tl}, \mathrm{Pb}$, and $\mathrm{Bi}$ were described with Stuttgart-type fully relativistic effective core potentials of Dolg and co-workers. ${ }^{209-211}$ Even when the core-valence basis sets were used for AE MP2 and CCSD calculations to describe the subvalence correlation, we applied exactly the same basis sets for the DFT methods for an unbiased comparison. Structures were characterized as true energy minima by the eigenvalues of the analytically calculated Hessian matrix.

2.3. Calculation of Errors. To quantitatively measure the deviation of the theoretical equilibrium internuclear distances from their experimental counterparts, we used a few common protocols. First, for each method, we calculated the mean unsigned error (MUE) and the mean signed error (MSE) defined as follows

$$
\begin{aligned}
\text { MUE }= & \frac{1}{M} \sum_{m=1}^{M}\left(\frac{2}{N(N-1)} \sum_{i=1}^{N-1} \sum_{j>i}^{N} \mid R_{i j} \text { (Theor. , } m\right) \\
& \left.-R_{i j}(\text { Exp. , } m) \mid\right) \\
\text { MSE }= & \frac{1}{M} \sum_{m=1}^{M}\left(\frac{2}{N(N-1)} \sum_{i=1}^{N-1} \sum_{j>i}^{N} R_{i j} \text { (Theor. , } m\right) \\
& \left.-R_{i j}(\text { Exp. , } m)\right)
\end{aligned}
$$

where $M$ is the number of molecules in the analyzed dataset, $N$ is the number of atoms in the molecule $(N=2$ for diatomic and $N=3$ for triatomic molecules), $R_{i j}$ (Exp., $m$ ) is the experimental internuclear distance between nuclei $i$ and $j$ in the molecule, $m$, and $R_{i j}$ (Theor., $m$ ) is its theoretical counterpart.

In addition to the two above-mentioned criteria, for the errors in internuclear distances obtained from each method, we also calculated the standard deviation $(\sigma)$ and the difference between the largest positive and negative deviation $(\delta=\operatorname{Max}-$ Min). These two values are necessary to understand the dispersion of the errors.

\section{RESULTS AND DISCUSSION}

We organize the results and discussion section as follows. First, we comment on the overall performance obtained for the combined dataset involving the internuclear distances of all diand triatomic molecules covered in the present study. Then, we assess an ability of methods in reproducing specific internuclear distances as those involving the s-metals, d-metals, and light 
and heavy elements. Afterward, we estimate the error in the absolute electronic energy arising from the use of different methods for geometric optimization and the SP energy evaluation, which corresponds to the maximum error associated with composite schemes.

3.1. Performance in Predicting All Internuclear Distances. The MSE and MUE for the 164 internuclear distances of the 83 diatomic and 27 triatomic DFT- and WFToptimized molecules listed in Tables 1 and 2 relative to the corresponding values derived from microwave spectroscopy measurements are presented in Figure 1. Among the local GGA

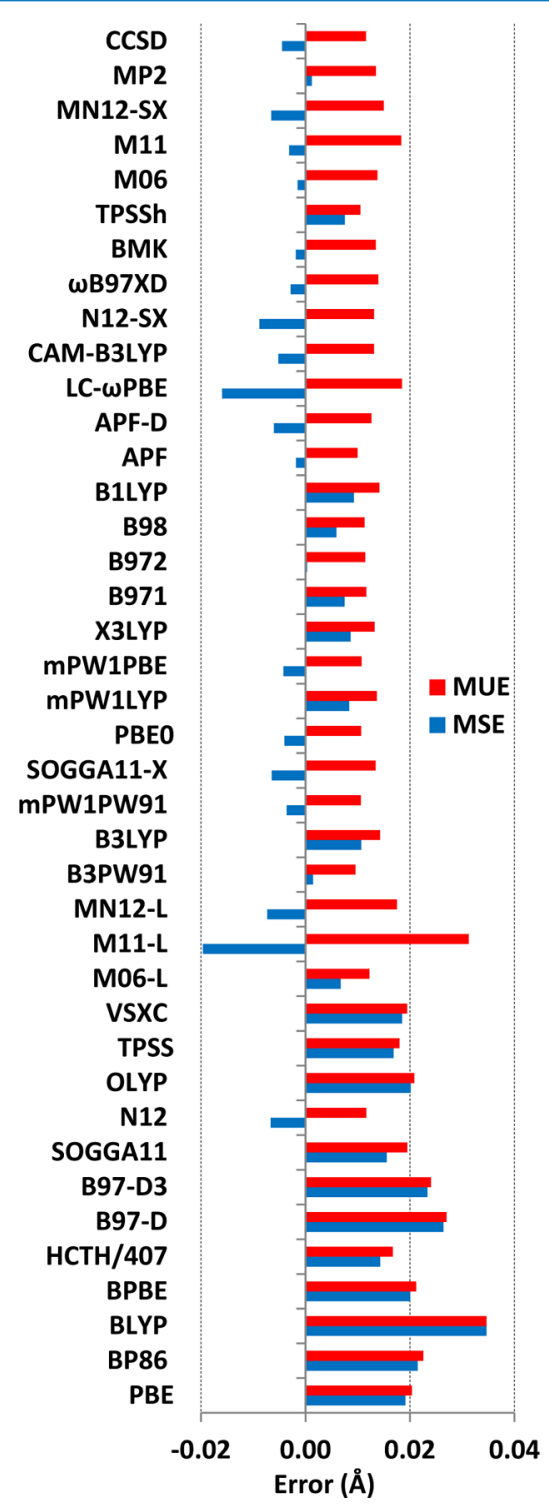

Figure 1. MSEs and MUEs for the 164 internuclear distances of the 83 diatomic and 27 triatomic DFT- and WFT-optimized molecules relative to the corresponding microwave spectroscopy data.

DFT methods, the smallest MUE of $0.012 \AA$ was detected for the recently developed nonseparable gradient N12 functional from the Minnesota group followed closely by the HCTH/407 functional with an MUE of $0.017 \AA$. While N12, with an MSE of $-0.007 \AA$, exhibits a small tendency toward underestimation of the distances, $\mathrm{HCTH} / 407$, with an MSE of $0.014 \AA$, results in distances that are, in general, too long. The largest errors in molecular structures were obtained by the BLYP functional. With the MUE and MSE of $0.035 \AA$, BLYP was found to overestimate the distances, which agrees with previous reports. ${ }^{47,48,254-257}$ All other tested local GGA DFT methods, including SOGGA11, PBE, OLYP, BPBE, BP86, B97-D3, and B97-D, resulted in similar MUEs in the range of $0.020-0.027$ A. With all seven methods, positive MSEs that were practically equal in magnitude to their corresponding MUEs were obtained, indicating the pronounced tendency toward overestimation of internuclear distances. Interestingly, the B97-D3 functional with an MUE of $0.024 \AA$ turned out to be superior to the B97-D functional with an MUE of $0.027 \AA$, indicating an improvement of the dispersion parameterization of D3 over D2. Despite the good accuracy obtained by the SOGGA11 method, this functional turned out to be particularly sensitive to an integration grid. The harmonic frequency calculation with the SOGGA11 functional on the three-dimensional structure optimized with the same method and the tighter-than-G09default "ultrafine" integration grid used in this work (pruned, 99 radial shells and 590 angular points per shell) resulted in the two imaginary frequencies of $i 1102.9 \mathrm{~cm}^{-1}$, both of which correspond to bending vibrations distorting the molecule from its linear structure. As this molecule was experimentally found to be linear with confirmation from all but the SOGGA11 functional, we concluded that the SOGGA11 method predicts incorrect harmonic frequencies. The origin of this issue is the use of reduced-quality integration grids by the G09 code during calculation of the second derivatives of the electronic energy. Even if the "ultrafine" integration grid was explicitly specified, a grid of lower quality was actually generated to calculate the second derivatives. Indeed, the harmonic frequency calculation that explicitly specified " $\mathrm{CPH}(\mathrm{Grid}=$ ultrafine)" was the only option that resulted in real frequencies.

From the local meta-GGA functionals, the lowest MUE of $0.012 \AA$ was found for the M06-L functional. The MSE of 0.007 $\AA$ for M06-L indicates that the functional has a small tendency to overestimate internuclear distances. Perhaps surprisingly, we found that the M11-L functional from the Minnesota group had the largest MUE of $0.031 \AA$. This functional's negative MSE of $-0.020 \AA$ suggests that it has a tendency to shorten the internuclear distances. All other meta-GGA functionals, including TPSS, MN12-L, and VSXC, performed rather uniformly with MUEs in the range of $0.018-0.019 \AA$. While the TPSS and VSXC methods with MSEs of 0.017 and $0.019 \AA$ provided distances that were too long, the MN12-L functional with an MSE of -0.007 A predicted a distance that was slightly short.

Among the hybrid and hybrid meta-GGA functionals, the lowest MUE of $0.010 \AA$ and practically vanishing MSEs of 0.001 and $-0.002 \AA$ were, respectively, found with the B3PW91 and APF functionals. An MUE of only $0.001 \AA$ higher was found with the mPW1PW91, PBE0, mPW1PBE, B972, B98, and TPSSh functionals. The first three of these functionals, namely mPW1PW91, PBE0, and MPW1PBE, with the MSE of $-0.004 \AA$ exhibited a small tendency toward overestimation of the internuclear distances. The B972 method predicted a practically vanishing MSE. The B98 and TPSSh functionals predicted positive MSEs of 0.006 and $0.008 \AA$, which were in general too long. Slightly higher MUEs of $0.012-0.014 \AA$ were detected for the B971 (MUE/MSE $=0.012 / 0.007 \AA$ ), SOGGA11-X (MUE/MSE $=0.013 /-0.006 \AA ̊)$, X3LYP $(\mathrm{MUE} / \mathrm{MSE}=0.013 / 0.009 \AA)$, APF-D $(\mathrm{MUE} / \mathrm{MSE}=$ $0.013 /-0.006 \AA$ A), CAM-B3LYP (MUE/MSE $=0.013 /-0.005$ 
$\AA ̊$ ), N12-SX (MUE/MSE $=0.013 /-0.009 \AA), \mathrm{BMK}(\mathrm{MUE} /$ MSE $=0.013 /-0.002 \AA)$, B3LYP $(\mathrm{MUE} / \mathrm{MSE}=0.014 / 0.011$ $\AA$ ), $\mathrm{mPW} 1 \mathrm{LYP}(\mathrm{MUE} / \mathrm{MSE}=0.014 / 0.008 \AA ̊$ ), B1LYP (MUE/ $\mathrm{MSE}=0.014 / 0.009 \AA), \omega \mathrm{B} 97 \mathrm{XD}(\mathrm{MUE} / \mathrm{MSE}=0.014 /-0.003$ $\AA$ ), and M06 (MUE/MSE $=0.014 /-0.001 \AA$ ) functionals. A larger MUE of $0.015 \AA$ was detected for the MN12-SX functional, which suggests a small tendency to underestimation as indicated by MSE of $-0.007 \AA$. On the other side of the scale, the largest MUE of $0.018 \AA$ was predicted by the M11 and CAM- $\omega$ PBE functionals for which the MSEs turned out to be -0.003 and $-0.016 \AA$, respectively. Interestingly, practically no influence of the Grimme dispersion correction was found for the PBE0, B3LYP, PBE, and other functionals. However, a significant difference in the predicted internuclear distances was obtained between APF and its dispersion-corrected counterpart, APF-D, as illustrated by a difference in the MUE of 0.003 $\AA$. A detailed analysis revealed that the difference between the APF and APF-D functionals was evident only for a limited number of molecules, including $\mathrm{Ag}$ halides, $\mathrm{BaO}, \mathrm{BaS}, \mathrm{BaF}$, $\mathrm{BaCl}, \mathrm{Cu}$ halides, and $\mathrm{Li}$ and $\mathrm{Na}$ halides and hydrides. For these molecules, the nonzero "Petersson-Frisch" dispersion en$\mathrm{ergy}^{240}$ was found whereas for all other species, the absolute zero dispersion energy was calculated. The observation that nonzero dispersion energy was obtained for all studied $\mathrm{Li}, \mathrm{Na}$, and $\mathrm{Ba}$ complexes whereas absolute zero dispersion energy was found for $\mathrm{Mg}, \mathrm{Ca}$, and $\mathrm{Sr}$ complexes is remarkable. Because the APF-D functional provides a larger MUE than APF does, we believe that, perhaps, additional adjustments of the dispersion parameters for this functional might be needed. Finally, for the two WFT methods for which AE were correlated, MP2 (AE) and CCSD (AE), MUEs of 0.013 and $0.012 \AA$ were found, which is comparable to that of the hybrid and hybrid-metaGGA DFT methods (Av. MUE of $0.013 \AA$ A) and significantly better than that of the meta-GGA methods (Av. MUE of 0.020 $\AA$ ) and local GGA methods (Av. MUE of $0.022 \AA$ ). This indicates that higher correlated WFT methods with larger basis sets have to be used to benchmark the performance of DFT methods in reproducing inorganic three-dimensional molecular structures.

Apart from the MUEs and MSEs, we also analyzed the dispersion of errors obtained for every method tested. For this purpose, in Figure 2, we show the standard deviation $(\sigma)$ and the absolute difference $(\delta)$ between the most positive and negative deviations. As expected, we found the largest dispersion of errors for the heavily empirically parameterized Minnesota functionals: M11-L resulted in $\sigma / \delta$ of $0.033 / 0.198$ $\AA$, followed by MN12-L with $\sigma / \delta$ of $0.022 / 0.152 \AA$ and SOGGA11 with $\sigma / \delta$ of $0.024 / 0.135 \AA$. Interestingly, a relatively large dispersion of errors $(\sigma / \delta$ of $0.019 / 0.135 \AA)$ was detected for the MP2 WFT method. The smallest dispersion of errors was found for the TPSSh, APF, mPW1PBE, PBE0, mPW1PW91, and B3PW91 functionals.

3.2. Analysis of Specific Internuclear Distances. We also analyzed the difference in performance of the tested methods in reproducing the structures of the molecules consisting of the lighter elements with $1-3$ periods and the heavier elements with 4-6 periods. The MSEs obtained for the molecules comprising the elements from the 1-3 groups and the elements from the 4-6 groups are presented in Figure S1; the corresponding MUEs are given in Figure S2; and the difference between the MUEs of the molecules comprising the lighter (periods 1-3) and heavier (periods 4-6) elements is depicted in Figure S3. In general, all the methods resulted in

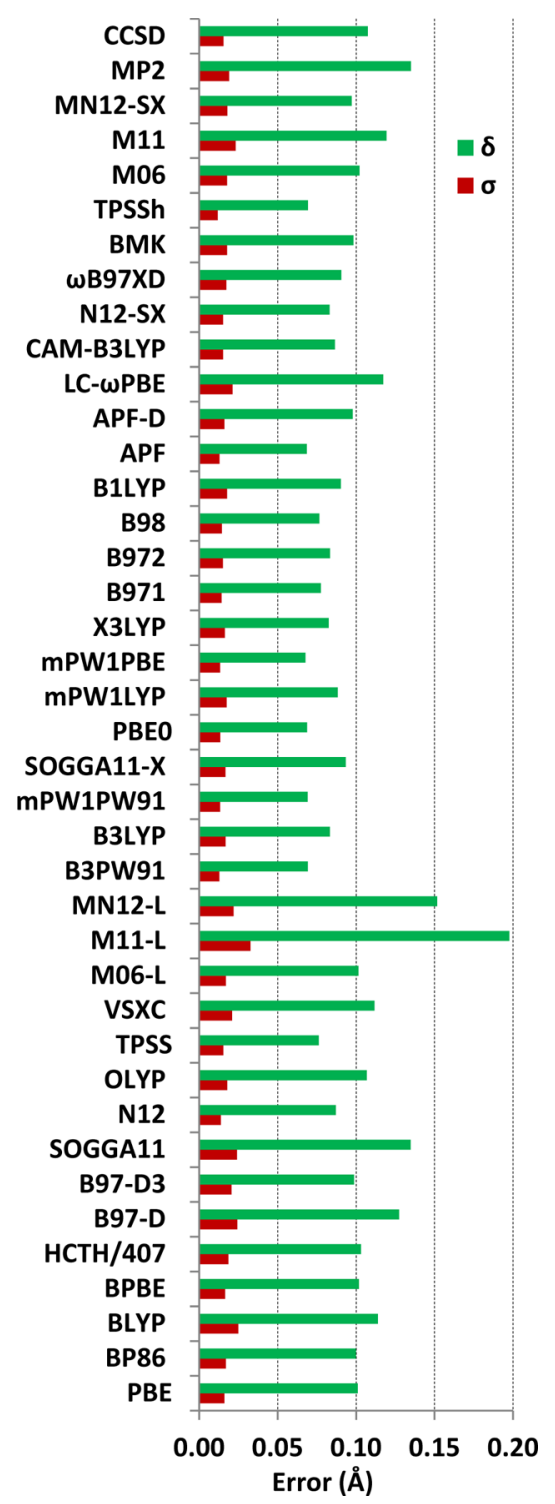

Figure 2. Standard deviation $(\sigma)$ and absolute difference between the largest positive and negative deviations $(\delta)$ for the 164 internuclear distances of the 83 diatomic and 27 triatomic DFT- and WFToptimized molecules relative to the corresponding microwave spectroscopy data.

larger MUEs for the structures of the molecules comprising heavier elements from the 4-6 groups. The average difference between the MUEs in reproducing the molecular structures comprising the heavier (4-6 groups) and lighter ( $1-3$ groups) elements turned out to be $0.007 \AA$. The smallest difference in the MUEs was obtained for N12-SX $(\Delta$ MUE $=0.001 \AA)$, mPW1PW91 $(\Delta$ MUE $=0.002 \AA)$, SOGGA11-X $(\Delta$ MUE $=$ $0.002 \AA)$, PBE0 $(\Delta \mathrm{MUE}=0.002 \AA)$, and mPW1PBE $(\Delta \mathrm{MUE}$ $=0.002 \AA$ ), indicating the robust performance of these methods across the different groups in the periodic table (see Figure S3). On the other hand, the largest difference in MUEs obtained for the structures comprising the elements of the 1-3 and 4-6 groups was obtained for SOGGA11 $(\Delta \mathrm{MUE}=0.019 \AA)$, BLYP $(\Delta \mathrm{MUE}=0.015 \AA), \operatorname{VSXC}(\Delta \mathrm{MUE}=0.014 \AA)$, and B97-D $(\Delta \mathrm{MUE}=0.014 \AA)$, indicating significantly better performance of these methods for the structures of the molecules comprising lighter elements. The larger MUEs obtained for the molecules comprising the heavier elements belonging to the $4-6$ groups 
can be explained by a variety of factors. For the correlated WFT methods, such as MP2 and CCSD, the core-valence correlation effects become more important for the molecules comprising elements from group 4 and higher, requiring larger and more flexible basis sets, especially in the subvalence region. ${ }^{194,258}$ For the semiempirical DFT methods, the absence of the heavy elements from the fourth period and above in the fitting set, as in the B3LYP method, might result in the larger errors documented for the molecules comprising these elements. Indeed, practically no difference in performance for molecules involving the lighter (1-3 groups) and heavier (4-6 groups) elements was found with the PBE and PBE0 methods for which no empirical parameters were used.

Finally, for all the methods, relativistic effects become more important and start influencing the molecular structures significantly. In the current work scalar relativistic effects were accounted for through using relativistic effective core potentials; although popular in the density functional theory research community, it might lead to some discrepancies with the $\mathrm{AE}$ scalar relativistic calculations. ${ }^{258}$ Moreover, the spin-orbit effects become nonnegligible even for the closed-shell species when the molecules comprise heavy elements, especially $5 \mathrm{p} / 6 \mathrm{p}$ elements. ${ }^{41,259-267}$ These effects may cancel themselves out when treated partially or neglected, leading to small errors. A detailed investigation of all these effects and their interplay is beyond the scope of the present study. Here, we restrict ourselves to the analysis of the errors in the structures of the molecules comprising the $5 p$ and $6 p$ elements. The MUEs and MSEs for the internuclear distances of the DFT- and WFToptimized molecules comprising the elements of the $5 p$ and $6 p$ block relative to the corresponding microwave spectroscopy data are given in Figure S4. Because the structures of these molecules are influenced by spin-orbit coupling, which we neglected in the present study, the best performing methods in our work most likely experienced some fortuitous cancellation of errors. The best-performing methods for these complexes turned out to be N12 (MSE/MUE $=0.000 / 0.014 \AA)$, mPW1PW91 (MSE/MUE $=0.001 / 0.014 \AA)$, PBE0 (MSE/ MUE $=0.000 / 0.014 \AA$ ), $\mathrm{mPW} 1 \mathrm{PBE}(\mathrm{MSE} / \mathrm{MUE}=-0.001 /$ $0.014 \AA$ ), and APF (MSE/MUE $=0.003 / 0.014 \AA$ ) followed closely by CCSD (MSE/MUE $=-0.004 / 0.015 \AA$ ). Because the calculations involving spin-orbit coupling are significantly more computationally expensive, the best-performing methods can be recommended to perform geometry optimizations while the spin-orbit contributions can be introduced later in a SP fashion. Similarly to what was found for the molecules comprising the elements of the 4-6 groups, quite large errors have been documented for SOGGA11, which might be explained by the fact that molecules containing the $5 p / 6 p$ elements were not a part of the training set used to parameterize this method.

Further, we analyzed the errors obtained for distances involving the 1 and 2 group metals as well as d metals. In Figure S5, the MSEs and MUEs for the internuclear distances involving the s-metals ( $1 / 2$ group elements) of the DFT- and WFT-optimized molecules relative to the corresponding microwave spectroscopy data are shown. The MSE/MUE averaged over all the tested methods turns out to be 0.008 / $0.016 \AA$, which is comparable with the average errors of 0.005 / $0.016 \AA$ obtained for a dataset containing all molecules (see section 3.1). Vanishing MSEs and small MUEs were obtained for PBE0 (MUE = $0.008 \AA$ ), followed closely by MPW1PW91 $($ MUE $=0.009 \AA)$, SOGGA11-X (MUE $=0.009 \AA)$,
mPW1PBE (MUE $=0.009 \AA)$, APF $($ MUE $=0.009 \AA)$, and N12-SX (MUE $=0.009 \AA$ ). The CCSD and MP2 methods slightly overestimated the distances of MSE/MUE of 0.013/ 0.013 and $0.012 / 0.014 \AA$, respectively. Finally, the largest errors were found for the B97D (MSE/MUE $=0.038 / 0.040 \AA$ ) functional. Remarkably, with the MSE/MUE of $-0.018 / 0.019$ $\AA$, the APF-D functional was found to provide the distances that are in general too short; meanwhile, its dispersion-free counterpart, APF, resulted in a significantly better MUE of $0.009 \AA$ and practically vanishing MSE. This indicates that the dispersion term in the APF-D functional should probably be reevaluated. In Figure S6, the MSEs and MUEs for the internuclear distances involving the d-metals $(\mathrm{Cu}$ and $\mathrm{Ag}$ ) of the DFT- and WFT-optimized molecules relative to the corresponding microwave spectroscopy data are shown. The MSE/MUE averaged over all the tested methods tuned out to be $0.007 / 0.018 \AA$, which is comparable to that obtained for the distances involving the s-metals. The best performing methods with an MUE of only $0.004 \AA$ and vanishing MSE turned out to be TPSS and its hybrid version, TPSSh, and the mPW1PBE method. Particularly, small MUEs of only $0.005 \AA$ and vanishing MSEs have also been obtained for the PBE, BP86, BPBE, mPW1PW91, PBE0, and APF methods. The worst performing method with an MSE/MUE of -0.052/0.052 $\AA$ turned out to be the MN12-L functional followed closely by SOGGA11 with an MSE/MUE of 0.050/0.050 Å. Remarkably, similarly to that found for the s-metals, the dispersion-corrected APD-F functional with an MSE/MUE of -0.035/0.037 $\AA$ was found to perform significantly worse compared with its dispersion-free counterpart, strongly indicating a need for reevaluation of the dispersion term in the APF-D method. When it comes to the WFT methods, the CCSD resulted in acceptable MSE/MUE both equal to $0.011 \AA$. Meanwhile, the MP2 methods with an MSE/MUE of $-0.037 / 0.037 \AA$ predicted distances that were rather too short. The poor performance of the MP2 method for transition metal complexes that we found here is in agreement with earlier reports. 257,268

3.3. Errors in Absolute Electronic Energies Arising from Geometry Optimization and SP Energy Evaluation with Various Methods. We performed a series of additional calculations to estimate the potential deviations in the absolute electronic energy because of the different methods used for geometry optimization and SP energy evaluation. The deviation in the absolute energy of a single compound corresponds to the maximum error in the relative energies obtained with the composite schemes because no cancellation between the reactants and products is assumed. First, we calculated the CCSD SP energy of three-dimensional molecular structures obtained with one of the best performing DFT functionals, PBE0. Then, we calculated the CCSD SP energy on the structures from one of the worst performers for molecular structures in the current study, M11-L. Finally, we calculated the difference between the CCSD SP energies from the two protocols described above, that is, CCSD/aug-cc-pwCVTZ// PBE0/aug-cc-pwCVTZ and CCSD/aug-cc-pwCVTZ//M11-L/ aug-cc-pwCVTZ, and the CCSD SP energy on a consistently optimized geometry. That is, CCSD/aug-cc-pwCVTZ// CCSD/aug-cc-pwCVTZ. The results are summarized in Figure 3 and Table S1. The average difference in electronic energy obtained with the CCSD/aug-cc-pwCVTZ//PBE0/aug-ccpwCVTZ protocol compared with the CCSD energies on consistently optimized geometries turned out to be $0.0 \mathrm{kcal} /$ 


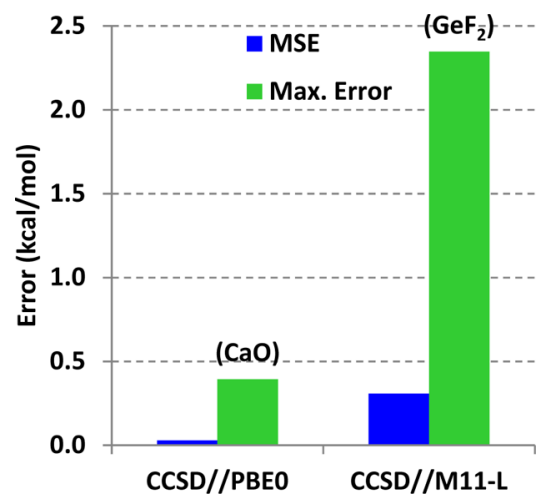

Figure 3. Difference in CCSD/aug-cc-pwCVTZ(-PP) SP energies on $\mathrm{PBE} 0 /$ aug-cc-pwCVTZ(-PP) and M11-L/aug-cc-pwCVTZ(-PP) compared with CCSD/aug-cc-pwCVTZ(-PP) SP energies on consistently optimized geometries.

mol, with a maximum deviation of $0.5 \mathrm{kcal} / \mathrm{mol}$ obtained for the $\mathrm{CaO}$ molecule. By contrast, the difference in energy obtained with the CCSD/aug-cc-pwCVTZ//M11-L/aug-ccpwCVTZ protocol compared with CCSD energies on consistently optimized geometries was significantly larger, 0.3 $\mathrm{kcal} / \mathrm{mol}$, with a maximum deviation of $2.3 \mathrm{kcal} / \mathrm{mol}$ obtained for the $\mathrm{GeF}_{2}$ molecule. These results suggest that an error of a few $\mathrm{kcal} / \mathrm{mol}$ in SP energies can easily be obtained even for relatively small systems if inaccurate three-dimensional structures are used.

\section{CONCLUSIONS}

We used very accurate gas-phase three-dimensional molecular structures of di- and triatomic molecules from microwave spectroscopy measurements to assess the accuracy of a battery of DFT and WFT methods with aug-cc-pwCVTZ basis sets. When we consider the performance of the methods in reproducing all internuclear distances in all the molecules, we find that the most accurate molecular structures were obtained by hybrid and hybrid meta-GGA functionals, with the B3PW91, APF, TPSSh, mPW1PW91, PBE0, mPW1PBE, B972, and B98 functionals providing the lowest errors. Among these functionals, we recommend $\mathrm{APF}$, mPW1PW91, mPW1PBE, and PBE0 because they resulted in the smallest errors for the subsets of internuclear distances that we studied as well as for the distances involving s-metals, d-metals, and 5p/6pcontaining molecules. Also, we found a negligible difference in performance for molecular structures containing lighter $(1-3$ periods) and heavier (4-6 elements) for these methods. The CCSD method predicted molecular geometries of similar quality although at considerably higher computational cost. Quite low errors were also found for the nonseparable gradient local-GGA functional N12, which we recommend for projects with low CPU budgets. We detected the largest errors with local GGA and meta-GGA functionals, namely BLYP and M11$\mathrm{L}$, suggesting that these methods not be used if accurate threedimensional molecular structures are the goal. Because we encountered some numerical problems with integrating the exchange-correlation part ${ }^{269,270}$ and obtained large dispersion of errors with some Minnesota functionals, particularly MN12L, M11, M06-L, SOGGA11, and VSXC, we also recommend that these methods not be used for geometry optimizations. The large and nonsystemic nature of the errors in internuclear distances is especially concerning in quantitative structureactivity relationship studies that correlate such parameters with chemical activity, for example, the correlation of the length of the $\mathrm{Ru}=\mathrm{C}$ bond in Grubbs complexes with their catalytic activity in olefin metathesis. ${ }^{271}$ Apart from these methods, we found that B97D performs poorly for distances involving smetals and should probably be avoided as well. The DFT-D3 dispersion correction was found to have a negligible effect on internuclear distances. By contrast, the APF-D dispersion correction led to significant shortening up to $0.064 \AA$ (AgI) of the bonds in $\mathrm{Ag}$ halides, $\mathrm{BaO}, \mathrm{BaS}, \mathrm{BaF}, \mathrm{BaCl}, \mathrm{Cu}$ halides, and $\mathrm{Li}$ and $\mathrm{Na}$ halides and hydrides. Given that these results do not agree well with very accurate structures derived from microwave spectroscopy, we believe that the dispersion correction in the APF-D method should be reconsidered.

When it comes to relatively large and nonrigid molecules for which intramolecular interactions are critical, significantly influencing the structure, particular recommendations on the geometric optimization method remain difficult to give. In our opinion, because of the large dispersion of errors that we found and problems related to noise in the integration of the exchange-correlation part of the functionals, the Minnesota models should either be avoided or applied with extreme caution. The DFT-D3 methods are perhaps a better choice than the Minnesota models. Experimental structures in the size range discussed here are available only from diffraction methods, which are significantly contaminated by the effects of molecular vibrations (GED) or librations and crystal-packing forces (X-ray), which may be comparable or even larger than the errors in internuclear distances for particular functional, making validation of DFT results a difficult prospect. Moreover, application of accurate WFT methods to obtain accurate geometries of relatively large molecules of 50-100 atoms to validate DFT methods is also impractical as robust results can be obtained only with the $\operatorname{CCSD}(\mathrm{T})$ method, relative large basis sets, and correlated subvalence electrons. Creation of a database of accurate molecular geometries for benchmarking of methods that require less-expensive computational chemistry methods would be a good subject for future work. Finally, we performed a series of additional calculations to estimate the potential errors in the absolute electronic energy from different methods used for geometry optimization and SP energy evaluation. Our calculations showed that an error of few $\mathrm{kcal} / \mathrm{mol}$ in SP energies can easily be obtained even in relatively small systems if inaccurate geometries are used.

\section{ASSOCIATED CONTENT}

\section{Supporting Information}

The Supporting Information is available free of charge on the ACS Publications website at DOI: 10.1021/acsomega.7b01203.

Figures S1-S6, Table S1 (mentioned in the main text), tabulated errors forming the basis of Figures $1-3$ and S1-S6, and Cartesian coordinates ( $)$ of PBE, BP86, BLYP, BPBE, HCTH/407, B97-D, B97-D3, SOGGA11, N12, OLYP, TPSS, VSXC, M06-L, M11-L, MN12-L, B3PW91, B3LYP, mPW1PW91, SOGGA11-X, PBE0, mPW1LYP, mPW1PBE, X3LYP, B971, B972, B98, B1LYP, APF, APF-D, LC- $\omega$ PBE, CAM-B3LYP, N12SX, $\omega$ B97X-D, BMK, TPSSh, M06, M11, MN12-SX, $\mathrm{MP2}$, and CCSD optimized geometries (PDF)

\section{AUTHOR INFORMATION}

\section{Corresponding Authors}

*E-mail: Yury.Minenkov@kaust.edu.sa (Y.M.). 
*E-mail: Luigi.Cavallo@kaust.edu.sa (L.C.).

\section{ORCID 1}

Yury Minenkov: 0000-0001-8993-056X

Luigi Cavallo: 0000-0002-1398-338X

\section{Notes}

The authors declare no competing financial interest.

\section{ACKNOWLEDGMENTS}

We are grateful to the reviewers for their critical comments and suggestions for improvement of this manuscript. The research reported in this publication was supported by funding from King Abdullah University of Science and Technology (KAUST). For computer time, this research used the resources of the Supercomputing Laboratory at King Abdullah University of Science and Technology (KAUST) in Thuwal, Saudi Arabia.

\section{REFERENCES}

(1) Jensen, F. Introduction to Computational Chemistry, 2nd ed.; Wiley: Chichester, England, 2006; pp 1-620.

(2) Cramer, C. J. Essentials of Computational Chemistry: Theories and Models, 2nd ed.; Wiley: Chichester, England, 2005; pp 1-618.

(3) Hehre, W. J.; Ditchfield, R.; Radom, L.; Pople, J. A. Molecular Orbital Theory of the Electronic Structure of Organic Compounds. V. Molecular Theory of Bond Separation. J. Am. Chem. Soc. 1970, 92, 4796-4801.

(4) Pople, J. A.; Head-Gordon, M.; Fox, D. J.; Raghavachari, K.; Curtiss, L. A. Gaussian-1 Theory: a General Procedure for Prediction of Molecular Energies. J. Chem. Phys. 1989, 90, 5622-5629.

(5) Curtiss, L. A.; Jones, C.; Trucks, G. W.; Raghavachari, K.; Pople, J. A. Gaussian-1 Theory of Molecular Energies for Second-Row Compounds. J. Chem. Phys. 1990, 93, 2537-2545.

(6) Curtiss, L. A.; Raghavachari, K.; Trucks, G. W.; Pople, J. A. Gaussian-2 Theory for Molecular Energies of First- and Second-Row Compounds. J. Chem. Phys. 1991, 94, 7221-7230.

(7) Curtiss, L. A.; Raghavachari, K.; Pople, J. A. Gaussian-2 Theory Using Reduced Møller-Plesset Orders. J. Chem. Phys. 1993, 98, 1293-1298.

(8) Minenkov, Y.; Sliznev, V. V.; Cavallo, L. Accurate Gas Phase Formation Enthalpies of Alloys and Refractories Decomposition Products. Inorg. Chem. 2017, 56, 1386-1401.

(9) Emel'yanenko, V. N.; Nagrimanov, R. N.; Solomonov, B. N.; Verevkin, S. P. Adamantanes: Benchmarking of Thermochemical Properties. J. Chem. Thermodyn. 2016, 101, 130-138.

(10) Goldsmith, C. F.; Magoon, G. R.; Green, W. H. Database of Small Molecule Thermochemistry for Combustion. J. Phys. Chem. A 2012, 116, 9033-9057.

(11) Bross, D. H.; Peterson, K. A. Composite Thermochemistry of Gas Phase U(VI)-Containing Molecules. J. Chem. Phys. 2014, 141, 244308.

(12) Emel'yanenko, V. N.; Zaitsau, D. H.; Shoifet, E.; Meurer, F.; Verevkin, S. P.; Schick, C.; Held, C. Benchmark Thermochemistry for Biologically Relevant Adenine and Cytosine. A Combined Experimental and Theoretical Study. J. Phys. Chem. A 2015, 119, 96809691.

(13) Somers, K. P.; Simmie, J. M. Benchmarking Compound Methods (CBS-QB3, CBS-APNO, G3, G4, W1BD) against the Active Thermochemical Tables: Formation Enthalpies of Radicals. J. Phys. Chem. A 2015, 119, 8922-8933.

(14) Verevkin, S. P.; Zaitsau, D. H.; Emel'yanenko, V. N.; Zhabina, A. A. Thermodynamic Properties of Glycerol: Experimental and Theoretical Study. Fluid Phase Equilib. 2015, 397, 87-94.

(15) Emel'yanenko, V. N.; Verevkin, S. P. Benchmark Thermodynamic Properties of 1,3-Propanediol: Comprehensive Experimental and Theoretical Study. J. Chem. Thermodyn. 2015, 85, 111-119.

(16) Emel'yanenko, V. N.; Zaitseva, K. V.; Agapito, F.; Simões, J. A. M.; Verevkin, S. P. Benchmark Thermodynamic Properties of
Methylanisoles: Experimental and Theoretical Study. J. Chem. Thermodyn. 2015, 85, 155-162.

(17) Emel'yanenko, V. N.; Pimerzin, A. A.; Turovtsev, V. V.; Verevkin, S. P. Benchmark Thermochemistry of N-Methylaniline. J. Phys. Chem. A 2015, 119, 2142-2152.

(18) Paulechka, E.; Kazakov, A. Efficient DLPNO-CCSD(T)-Based Estimation of Formation Enthalpies for C-, H-, O-, and N-Containing Closed-Shell Compounds Validated against Critically Evaluated Experimental Data. J. Phys. Chem. A 2017, 121, 4379-4387.

(19) Karton, A.; Rabinovich, E.; Martin, J. M. L.; Ruscic, B. W4 Theory for Computational Thermochemistry: In Pursuit of Confident Sub-kj/mol Predictions. J. Chem. Phys. 2006, 125, 144108.

(20) Karton, A.; Tarnopolsky, A.; Lamère, J. F.; Schatz, G. C.; Martin, J. M. L. Highly Accurate First-Principles Benchmark Data Sets for the Parametrization and Validation of Density Functional and Other Approximate Methods. Derivation of a Robust, Generally Applicable, Double-Hybrid Functional for Thermochemistry and Thermochemical Kinetics. J. Phys. Chem. A 2008, 112, 12868-12886.

(21) Karton, A.; Gruzman, D.; Martin, J. M. L. Benchmark Thermochemistry of the $\mathrm{C}_{\mathrm{n}} \mathrm{H}_{2 \mathrm{n}+2}$ Alkane Isomers $(\mathrm{N}=2-8)$ and Performance of DFT and Composite $\mathrm{Ab}$ Initio Methods for Dispersion-Driven Isomeric Equilibria. J. Phys. Chem. A 2009, 113, 8434-8447.

(22) Karton, A.; Daon, S.; Martin, J. M. L. W4-11: A HighConfidence Benchmark Dataset for Computational Thermochemistry Derived from First-Principles W4 Data. Chem. Phys. Lett. 2011, 510, $165-178$.

(23) Minenkov, Y.; Occhipinti, G.; Jensen, V. R. Metal-Phosphine Bond Strengths of the Transition Metals: A Challenge for DFT. J. Phys. Chem. A 2009, 113, 11833-11844.

(24) Minenkov, Y.; Occhipinti, G.; Heyndrickx, W.; Jensen, V. R. The Nature of the Barrier to Phosphane Dissociation from Grubbs Olefin Metathesis Catalysts. Eur. J. Inorg. Chem. 2012, 1507-1516.

(25) Minenkov, Y.; Chermak, E.; Cavallo, L. Accuracy of DLPNO$\operatorname{CCSD}(\mathrm{T})$ Method for Noncovalent Bond Dissociation Enthalpies from Coinage Metal Cation Complexes. J. Chem. Theory Comput. 2015, 11, 4664-4676.

(26) Minenkov, Y.; Chermak, E.; Cavallo, L. Troubles in the Systematic Prediction of Transition Metal Thermochemistry with Contemporary Out-of-the-Box Methods. J. Chem. Theory Comput. 2016, 12, 1542-1560.

(27) Sieffert, N.; Bühl, M. Noncovalent Interactions in a TransitionMetal Triphenylphosphine Complex: A Density Functional Case Study. Inorg. Chem. 2009, 48, 4622-4624.

(28) Xu, X.; Zhang, W.; Tang, M.; Truhlar, D. G. Do Practical Standard Coupled Cluster Calculations Agree Better Than KohnSham Calculations with Currently Available Functionals When Compared to the Best Available Experimental Data for Dissociation Energies of Bonds to 3d Transition Metals? J. Chem. Theory Comput. 2015, 11, 2036-2052.

(29) Goerigk, L.; Grimme, S. A Thorough Benchmark of Density Functional Methods for General Main Group Thermochemistry, Kinetics, and Noncovalent Interactions. Phys. Chem. Chem. Phys. 2011, $13,6670-6688$

(30) Zhao, Y.; Truhlar, D. G. Applications and Validations of the Minnesota Density Functionals. Chem. Phys. Lett. 2011, 502, 1-13.

(31) Schultz, N. E.; Zhao, Y.; Truhlar, D. G. Databases for Transition Element Bonding: Metal-Metal Bond Energies and Bond Lengths and Their Use to Test Hybrid, Hybrid Meta, and Meta Density Functionals and Generalized Gradient Approximations. J. Phys. Chem. A 2005, 109, 4388-4403.

(32) Cramer, C. J.; Truhlar, D. G. Density Functional Theory for Transition Metals and Transition Metal Chemistry. Phys. Chem. Chem. Phys. 2009, 11, 10757-10816.

(33) Averkiev, B. B.; Zhao, Y.; Truhlar, D. G. Binding Energy of $d^{10}$ Transition Metals to Alkenes by Wave Function Theory and Density Functional Theory. J. Mol. Catal. A: Chem. 2010, 324, 80-88.

(34) Zhang, W.; Truhlar, D. G.; Tang, M. Tests of ExchangeCorrelation Functional Approximations against Reliable Experimental 
Data for Average Bond Energies of 3d Transition Metal Compounds.

J. Chem. Theory Comput. 2013, 9, 3965-3977.

(35) Tarnopolsky, A.; Karton, A.; Sertchook, R.; Vuzman, D.; Martin, J. M. L. Double-Hybrid Functionals for Thermochemical Kinetics. J. Phys. Chem. A 2008, 112, 3-8.

(36) Liakos, D. G.; Sparta, M.; Kesharwani, M. K.; Martin, J. M. L.; Neese, F. Exploring the Accuracy Limits of Local Pair Natural Orbital Coupled-Cluster Theory. J. Chem. Theory Comput. 2015, 11, 15251539 .

(37) Tortorella, S.; Talamo, M. M.; Cardone, A.; Pastore, M.; De Angelis, F. Benchmarking DFT and Semi-Empirical Methods for a Reliable and Cost-Efficient Computational Screening of Benzofulvene Derivatives as Donor Materials for Small-Molecule Organic Solar Cells. J. Phys.: Condens. Matter 2016, 28, 074005.

(38) Shi, R.; Huang, X.; Su, Y.; Lu, H.-G.; Li, S.-D.; Tang, L.; Zhao, J. Which Density Functional Should Be Used to Describe Protonated Water Clusters? J. Phys. Chem. A 2017, 121, 3117-3127.

(39) Kubiček, K.; Veedu, S. T.; Storozhuk, D.; Kia, R; Techert, S. Geometric and Electronic Properties in a Series of Phosphorescent Heteroleptic $\mathrm{Cu}(\mathrm{I})$ Complexes: Crystallographic and Computational Studies. Polyhedron 2017, 124, 166-176.

(40) Cypryk, M.; Gostyński, B. Computational Benchmark for Calculation of Silane and Siloxane Thermochemistry. J. Mol. Model. 2016, 22, 35.

(41) Wang, J.; Bai, F.-Q.; Xia, B.-H.; Zhang, H.-X.; Cui, T. Accurate Simulation of Geometry, Singlet-Singlet and Triplet-Singlet Excitation of Cyclometalated Iridium(III) Complex. J. Mol. Model. 2014, 20, 2108

(42) Tentscher, P. R.; Arey, J. S. Geometries and Vibrational Frequencies of Small Radicals: Performance of Coupled Cluster and More Approximate Methods. J. Chem. Theory Comput. 2012, 8, 21652179.

(43) Hirva, P.; Haukka, M.; Jakonen, M.; Moreno, M. A. DFT Tests for Group 8 Transition Metal Carbonyl Complexes. J. Mol. Model. 2008, 14, 171-181.

(44) Minenkov, Y.; Singstad, Å.; Occhipinti, G.; Jensen, V. R. The Accuracy of DFT-Optimized Geometries of Functional Transition Metal Compounds: A Validation Study of Catalysts for Olefin Metathesis and Other Reactions in the Homogeneous Phase. Dalton Trans. 2012, 41, 5526-5541.

(45) Girichev, G. V.; Giricheva, N. I.; Koifman, O. I.; Minenkov, Y. V.; Pogonin, A. E.; Semeikin, A. S.; Shlykov, S. A. Molecular Structure and Bonding in Octamethylporphyrin Tin(II), $\mathrm{SnN}_{4} \mathrm{C}_{28} \mathrm{H}_{28}$. Dalton Trans. 2012, 41, 7550-7558.

(46) Bühl, M.; Kabrede, H. Geometries of Transition-Metal Complexes from Density-Functional Theory. J. Chem. Theory Comput. 2006, 2, 1282-1290.

(47) Bühl, M.; Reimann, C.; Pantazis, D. A.; Bredow, T.; Neese, F. Geometries of Third-Row Transition-Metal Complexes from DensityFunctional Theory. J. Chem. Theory Comput. 2008, 4, 1449-1459.

(48) Waller, M. P.; Braun, H.; Hojdis, N.; Bühl, M. Geometries of Second-Row Transition-Metal Complexes from Density-Functional Theory. J. Chem. Theory Comput. 2007, 3, 2234-2242.

(49) Larsen, E.; Madsen, A. Ø.; Kofod, P.; Song, Y. S. Making a Robust Carbon-Cobalt(III) Bond. Inorg. Chem. 2009, 48, 71597164 .

(50) Huang, H.; Zhang, T.; Zhang, J.; Wang, L. Density Functional Theoretical Study of Transition Metal Carbohydrazide Perchlorate Complexes. Chem. Phys. Lett. 2010, 487, 200-203.

(51) Machura, B.; Jaworska, M.; Kruszynski, R. X-Ray and Electronic Structure of the $\left[\operatorname{ReCl}_{3}(\mathrm{pzH})_{2}\left(\mathrm{PPh}_{3}\right)\right]$ and $\left[\operatorname{ReCl}_{3}(3,5-\right.$ $\left.\left.\mathrm{Me}_{2} \mathrm{pzH}\right)_{2}\left(\mathrm{PPh}_{3}\right)\right]$ Complexes. Polyhedron 2004, 23, 1819-1827.

(52) Machura, B.; Jaworska, M.; Kruszynski, R. DFT Calculation and X-Ray Structure of the $\left[\mathrm{ReCl}_{3}(\mathrm{pzH})_{3}\right]$ Complex. Polyhedron 2004, 23, 2005-2011.

(53) Jiménez-Hoyos, C. A.; Janesko, B. G.; Scuseria, G. E. Evaluation of Range-Separated Hybrid and Other Density Functional Approaches on Test Sets Relevant for Transition Metal-Based Homogeneous Catalysts. J. Phys. Chem. A 2009, 113, 11742-11749.
(54) Jacobsen, H. Hydrogen and Dihydrogen Bonding of Transition Metal Hydrides. Chem. Phys. 2008, 345, 95-102.

(55) Kulkarni, A. D.; Truhlar, D. G. Performance of Density Functional Theory and Møller-Plesset Second-Order Perturbation Theory for Structural Parameters in Complexes of Ru. J. Chem. Theory Comput. 2011, 7, 2325-2332.

(56) Rydberg, P.; Olsen, L. The Accuracy of Geometries for Iron Porphyrin Complexes from Density Functional Theory. J. Phys. Chem. A 2009, 113, 11949-11953.

(57) Vilkov, L. V.; Pentin, Y. A. Physical Research Methods in Chemistry. Structural Methods and Optical Spectroscopy; Mir: Moscow, 2003; pp 1-683.

(58) Novikov, V. P.; Sipachev, V. A.; Kulikova, E. I.; Vilkov, L. V. A Comparison of Amplitudes and Shrinkage Corrections for $\mathrm{C}_{6} \mathrm{Cl}_{3}\left(\mathrm{NO}_{2}\right)_{3}$ Calculated Using Conventional and New Procedures. J. Mol. Struct. 1993, 301, 29-36.

(59) Sipachev, V. A. Anharmonic Corrections to Structural Experiment Data. Struct. Chem. 2000, 11, 167-172.

(60) Sipachev, V. A.; Khaikin, L. S.; Grikina, O. E.; Nikitin, V. S.; Trætteberg, M. Structure, Spectra and Internal Rotation of Bis(Trimethylsilyl) Acetylene: Spectral Analysis by Scaling QuantumChemical Force Fields and Two Methods for Calculating Vibrational Effects. J. Mol. Struct. 2000, 523, 1-22.

(61) Sipachev, V. A. Local Centrifugal Distortions Caused by Internal Motions of Molecules. J. Mol. Struct. 2001, 567, 67-72.

(62) Sipachev, V. A. The Use of Quantum-Mechanical Third-Order Force Constants in Structural Studies. J. Mol. Struct. 2004, 693, 235240.

(63) Perdew, J. P.; Burke, K.; Ernzerhof, M. Generalized Gradient Approximation Made Simple. Phys. Rev. Lett. 1996, 77, 3865-3868.

(64) Perdew, J. P.; Burke, K.; Ernzerhof, M. Generalized Gradient Approximation Made Simple [Phys. Rev. Lett. 77, 3865 (1996)]. Phys. Rev. Lett. 1997, 78, 1396.

(65) Becke, A. D. Density-Functional Exchange-Energy Approximation with Correct Asymptotic Behavior. Phys. Rev. A 1988, 38, 3098-3100.

(66) Lee, C.; Yang, W.; Parr, R. G. Development of the Colle-Salvetti Correlation-Energy Formula into a Functional of the Electron Density. Phys. Rev. B 1988, 37, 785-789.

(67) Stephens, P. J.; Devlin, F. J.; Chabalowski, C. F.; Frisch, M. J. Ab Initio Calculation of Vibrational Absorption and Circular Dichroism Spectra Using Density Functional Force Fields. J. Phys. Chem. 1994, 98, 11623-11627.

(68) Becke, A. D. Density-Functional Thermochemistry. III. The Role of Exact Exchange. J. Chem. Phys. 1993, 98, 5648-5652.

(69) Lovas, F. J.; Tiemann, E.; Coursey, J. S.; Kotochigova, S. A.; Chang, J.; Olsen, K.; Dragoset, R. A. NIST Standard Reference Database 114. Diatomic Spectral Database, version 2.1 [Online]; National Institute of Standards and Technology: Gaithersburg, MD, 2002. Available: http://physics.nist.gov/Diatomic.

(70) Lovas, F. J.; Coursey, J. S.; Kotochigova, S. A.; Chang, J.; Olsen, K.; Dragoset, R. A. NIST Standard Reference Database 117. Triatomic Spectral Database, version 2.0 [Online]; National Institute of Standards and technology: Gaithersburg, MD, 2003. Available: http://physics.nist.gov/Triatomic.

(71) Hoeft, J.; Lovas, F. J.; Tiemann, E.; Törring, T. Die Mikrowellen-Rotationsspektren des $\mathrm{AgCl}, \mathrm{AgBr}$ und $\mathrm{AgJ} . \mathrm{Z}$. Naturforsch., A: Astrophys., Phys. Phys. Chem. 1971, 26, 240-244.

(72) Krisher, L. C.; Norris, W. G. Microwave Spectrum of Silver Chloride. J. Chem. Phys. 1966, 44, 391-394.

(73) Hoeft, J.; Lovas, F. J.; Tiemann, E.; Törring, T. The Rotational Spectra and Dipole Moments of $\mathrm{AgF}$ and $\mathrm{CuF}$ by Microwave Absorption. Z. Naturforsch., A: Astrophys., Phys. Phys. Chem. 1970, 25, $35-39$.

(74) Hoeft, J.; Nair, K. P. R. Millimeter-Wave Rotational Transitions and Molecular Constants of the Diatomic Silver Iodide. Chem. Phys. Lett. 1986, 129, 538-540.

(75) Wyse, F. C.; Gordy, W. Millimeter Wave Rotational Spectra of $\mathrm{AlCl}, \mathrm{AlBr}$, and AlI. J. Chem. Phys. 1972, 56, 2130. 
(76) Wyse, F. C.; Gordy, W.; Pearson, E. F. Millimeter and Submillimeter Wave Spectrum and Molecular Constants of Aluminum Monofluoride. J. Chem. Phys. 1970, 52, 3887.

(77) Lide, D. R. High-Temperature Microwave Spectroscopy: AlF and AlCl. J. Chem. Phys. 1965, 42, 1013.

(78) Hoeft, J.; Lovas, F. J.; Tiemann, E.; Törring, T. Microwave Absorption Spectra of AlF, GaF, InF, and TIF. Z. Naturforsch., A: Astrophys., Phys. Phys. Chem. 1970, 25, 1029-1035.

(79) Endo, Y.; Saito, S.; Hirota, E. Microwave Spectroscopy of Boron Chloride $(\mathrm{BCl})$. The Chlorine Nuclear Quadrupole Coupling Constant. Bull. Chem. Soc. Jpn. 1983, 56, 3410-3414.

(80) Lovas, F. J.; Johnson, D. R. Microwave Spectrum of BF. J. Chem. Phys. 1971, 55, 41.

(81) Wharton, L.; Klemperer, W. Microwave Spectrum of BaO. J. Chem. Phys. 1963, 38, 2705.

(82) Hocking, W. H.; Pearson, E. F.; Creswell, R. A.; Winnewisser, G. Millimeter Wave Spectra of the Alkaline Earth Metal Oxides: $\mathrm{BaO}$, SrO, and CaO. J. Chem. Phys. 1978, 68, 1128-1134.

(83) Helms, D. A.; Winnewisser, M.; Winnewisser, G. Millimeter Wave Spectrum of Barium Sulfide in a Low-Pressure Flame. Current Millimeter Wave Measurements of High-Temperature Species. J. Phys. Chem. 1980, 84, 1758-1765.

(84) Melendres, C. A.; Hebert, A. J.; Street, K. Radio-Frequency Stark Spectra and Dipole Moment of BaS. J. Chem. Phys. 1969, 51, 855.

(85) Willis, R. E.; Clark, W. W. Millimeter Wave Measurements of the Rotational Spectra of $\mathrm{ClF}, \mathrm{BrF}, \mathrm{BrCl}, \mathrm{ICl}$, and IBr. J. Chem. Phys. 1980, 72, 4946-4950.

(86) Le Floch, A. Revised Molecular Constants for the Ground State of CO. Mol. Phys. 1991, 72, 133-144.

(87) Bogey, M.; Demuynck, C.; Destombes, J. L. Millimeter and Submillimeter Wave Spectrum of $\mathrm{CS}^{1} \Sigma$ in High Vibrational-States: Isotopic Dependence of Dunham Coefficients. J. Mol. Spectrosc. 1982, $95,35-42$.

(88) McGurk, J.; Tigelaar, H. L.; Rock, S. L.; Norris, C. L.; Flygare, W. H. Detection, Assignment of the Microwave Spectrum and the Molecular Stark and Zeeman Effects in CSe, and the Zeeman Effect and Sign of the Dipole Moment in CS. J. Chem. Phys. 1973, 58, 14201424.

(89) Creswell, R. A.; Hocking, W. H.; Pearson, E. F. Millimeter Wave Spectrum of CaO. Chem. Phys. Lett. 1977, 48, 369-371.

(90) Manson, E. L.; De Lucia, F. C.; Gordy, W. Millimeter-Wave Spectrum and Molecular Constants of Cuprous Bromide. J. Chem. Phys. 1975, 63, 2724-2726.

(91) Manson, E. L.; De Lucia, F. C.; Gordy, W. Millimeter- and Submillimeter-Wave Spectrum and Molecular Constants of Cuprous Chloride. J. Chem. Phys. 1975, 62, 1040-1043.

(92) Manson, E. L.; De Lucia, F. C.; Gordy, W. Millimeter- and Submillimeter-Wave Spectrum and Molecular Constants of Cuprous Iodide. J. Chem. Phys. 1975, 62, 4796-4798.

(93) Nair, K. P. R.; Schütze-Pahlmann, H.-U.; Hoeft, J. MillimeterWave Rotational Spectrum and Molecular Constants of Diatomic Gallium Bromide. Chem. Phys. Lett. 1981, 80, 149-152.

(94) Tiemann, E.; Hoeft, J.; Grasshoff, M. Hyperfeinstruktur im Rotati onsspektrum des GaCl. Z. Naturforsch., A: Phys., Phys. Chem., Kosmophys. 1972, 27, 753.

(95) Nair, K. P. R.; Schütze-Pahlmann, H.-U.; Hoeft, J. MillimeterWave Rotational Spectrum and Molecular Constants of Diatomic Gallium Iodide. Chem. Phys. Lett. 1980, 70, 583-586.

(96) Törring, T. Das Mikrowellenrotationsspektrum Des GeO. Z. Naturforsch., A: Astrophys., Phys. Phys. Chem. 1966, 21, 287.

(97) Raymonda, J. W.; Muenter, J. S.; Klemperer, W. A. Electric Dipole Moment of $\mathrm{SiO}$ and GeO. J. Chem. Phys. 1970, 52, 3458.

(98) Stieda, W. U.; Tiemann, E.; Törring, T.; Hoeft, J. Adiabatische Korrektur der Born-Oppenheimer-Näherung beim GeS und GeSe/ Adiabatic Correction of the Born-Oppenheimer Approximation for GeS and GeSe. Z. Naturforsch., A: Phys., Phys. Chem., Kosmophys. 1976, 31, 374-380.
(99) Hoeft, J.; Lovas, F. J.; Tiemann, E.; Törring, T. Notizen: Microwave Spectrum of BaO. Z. Naturforsch., A: Astrophys., Phys. Phys. Chem. 1970, 25, 1750.

(100) Rank, D. H.; Fink, U.; Wiggins, T. A. High Resolution Measurements on the Infrared Absorption Spectrum of HBr. J. Mol. Spectrosc. 1965, 18, 170-183.

(101) Rank, D. H.; Rao, B. S.; Wiggins, T. A. Molecular Constants of $\mathrm{HCl}^{35}$. J. Mol. Spectrosc. 1965, 17, 122.

(102) De Lucia, F. C.; Helminger, P.; Gordy, W. Submillimeter-Wave Spectra and Equilibrium Structures of the Hydrogen Halides. Phys. Rev. A 1971, 3, 1849.

(103) Webb, D. U.; Rao, K. N. Vibration Rotation Bands of Heated Hydrogen Halides. J. Mol. Spectrosc. 1968, 28, 121-124.

(104) De Leluw, F. H.; Dymanus, A. Magnetic Properties and Molecular Quadrupole Moment of HF and $\mathrm{HCl}$ By molecular-Beam Electric-Resonance Spectroscopy. J. Mol. Spectrosc. 1973, 48, 427-445.

(105) Muenter, J. S.; Klemperer, W. Hyperfine Structure Constants of HF and DF. J. Chem. Phys. 1970, 52, 6033.

(106) Van Dijk, F. A.; Dymanus, A. The Electric Dipole Moment of HI and HBr. Chem. Phys. Lett. 1970, 5, 387-389.

(107) Herbst, E.; Steinmetz, W. Dipole Moment of ICI. J. Chem. Phys. 1972, 56, 5342.

(108) Tiemann, E.; Hoeft, J.; Törring, T. Das Rotationsspektrum des JF/Rotational Spectrum of IF. Z. Naturforsch., A: Phys., Phys. Chem., Kosmophys. 1973, 28, 1405-1407.

(109) Tiemann, E.; Köhler, U.; Hoeft, J. Zum Rotationsspektrum des InBr/On the Rotational Spectrum of InBr. Z. Naturforsch., A: Phys., Phys. Chem., Kosmophys. 1977, 32, 6-9.

(110) Hoeft, J. Das Mikrowellenrotationsspektrum Des Indiummonochlorids. Z. Phys. 1961, 163, 262.

(111) Delvigne, G. A. L.; de Wijn, H. W. Microwave Rotational Spectrum of Indium Monochloride. J. Chem. Phys. 1966, 45, 3318.

(112) Tiemann, E.; Hoeft, J.; Törring, T. Elektrisches dipolmoment von InCl/Electric dipole moment of InCl. Z. Naturforsch., A: Phys., Phys. Chem., Kosmophys. 1972, 27, 869.

(113) Schenk, B.; Tiemann, E.; Hoeft, J. Hyperfeinstruktur des Rotationsspektrums bei zwei vergleichbaren Quadrupolkopplungskonstanten: InJ. Z. Naturforsch., A: Astrophys., Phys. Phys. Chem. 1970, 25, 1827.

(114) Hebert, A. J.; Breivogel, F. W.; Street, K. Radio-Frequency and Microwave Spectra of LiBr by the Molecular-Beam Electric-Resonance Method. J. Chem. Phys. 1964, 41, 2368.

(115) Hebert, A. J.; Breivogel, F. W.; Street, K. Erratum: RadioFrequency and Microwave Spectra of $\mathrm{LiBr}$ by the Molecular-Beam Electric-Resonance Method. J. Chem. Phys. 1967, 47, 2202.

(116) Pearson, E. F.; Gordy, W. Millimeter- and Submillimeter-Wave Spectra and Molecular Constants of LiF and LiCl. Phys. Rev. 1969, $177,52$.

(117) Hebert, A. J.; Lovas, F. J.; Melendres, C. A.; Hollowell, C. D.; Story, T. L.; Street, K. Dipole Moments of Some Alkali Halide Molecules by Molecular Beam Electric Resonance Method. J. Chem. Phys. 1968, 48, 2824.

(118) Russell, A. M. Magnetic Moments Due to Rotation in $\mathrm{Li}^{6} \mathrm{~F}$ and Li ${ }^{7}$ F. Phys. Rev. 1958, 111, 1558-1567.

(119) Plummer, G. M.; Herbst, E.; De Lucia, F. C. Submillimeter Spectra and Molecular Constants of ${ }^{6} \mathrm{LiH},{ }^{7} \mathrm{LiH},{ }^{6} \mathrm{LiD}$, and ${ }^{7} \mathrm{LiD}$. J. Chem. Phys. 1984, 81, 4893-4897.

(120) Breivogel, F. W.; Hebert, A. J.; Street, K. Radio-Frequency and Microwave Spectra of ${ }^{6} \mathrm{Li}^{127} \mathrm{I}$ by the Molecular-Beam ElectricResonance Method. J. Chem. Phys. 1965, 42, 1555.

(121) Törring, T.; Hoeft, J. The Microwave Absorption Spectrum of MgO. Chem. Phys. Lett. 1986, 126, 477-480.

(122) Rusk, J. R.; Gordy, W. Millimeter Wave Molecular Beam Spectroscopy: Alkali Bromides and Iodides. Phys. Rev. 1962, 127, 817.

(123) Clouser, P. L.; Gordy, W. Millimeter-Wave Molecular-Beam Spectroscopy: Alkali Chlorides. Phys. Rev. 1964, 134, A863.

(124) De Leeuw, F. H.; van Wachem, R; Dymanus, A. RadioFrequency Spectra of $\mathrm{NaCl}$ by the Molecular-Beam Electric Resonance Method. J. Chem. Phys. 1970, 53, 981. 
(125) Bauer, R. K.; Lew, H. Rotational Constants and Electric Dipole Moment of NaF. Can. J. Phys. 1963, 41, 1461-1469.

(126) Hollowell, C. D.; Hebert, A. J.; Street, K. Radio-Frequency and Microwave Spectra of NaF by the Molecular-Beam Electric-Resonance Method. J. Chem. Phys. 1964, 41, 3540.

(127) Sastry, K. V. L. N.; Herbst, E.; de Lucia, F. C. Laboratory Measurements of Millimeter and Submillimeter Transitions of Sodium Hydride and Sodium Deuteride. Astrophys. J. 1981, 248, L53-L55.

(128) Sastry, K. V. L. N.; Herbst, E.; De Lucia, F. C. The Millimeter Wave Spectra of NaH and NaD. J. Chem. Phys. 1981, 75, 4753-4757.

(129) Wyse, F. C.; Gordy, W. Rotational Spectrum of PN. Bull. Am. Phys. Soc. 1972, 17, 575.

(130) Wyse, F. C.; Manson, E. L.; Gordy, W. Millimeter Wave Rotational Spectrum and Molecular Constants of ${ }^{31} \mathrm{P}^{14} \mathrm{~N}$. J. Chem. Phys. 1972, 57, 1106.

(131) Raymonda, J.; Klemperer, W. Molecular Beam Electric Resonance Spectrum of ${ }^{31} \mathrm{P}^{14} \mathrm{~N}$. J. Chem. Phys. 1971, 55, 232.

(132) Törring, T. Notizen: Das Mikrowellenrotationsspektrum des Bleimonoxids. Z. Naturforsch., A: Astrophys., Phys. Phys. Chem. 1964, $19,1426$.

(133) Hoeft, J.; Lovas, F.; Tiemann, E.; Tischer, R.; Törring, T. Elektrisches Dipolmoment und Mikrowellenrotationsspektrum von $\mathrm{SnO}, \mathrm{SnS}, \mathrm{PbO}$ und PbS. Z. Naturforsch., A: Astrophys., Phys. Phys. Chem. 1969, 24, 1222.

(134) Hoeft, J. Notizen: Das Mikrowellenrotationsspektrum Des Bleimonosulfids. Z. Naturforsch., A: Astrophys., Phys. Phys. Chem. 1964, 19, 1134.

(135) Hoeft, J.; Manns, K. Das Mikrowellenrotationsspektrum Des PbSe. Z. Naturforsch., A: Astrophys., Phys. Phys. Chem. 1966, 21, 1884.

(136) Tiemann, E.; Hoeft, J.; Schenk, B. Das Mikrowellenrotationsspektrum des PbTe. Z. Naturforsch., A: Astrophys., Phys. Phys. Chem. 1969, 24, 787.

(137) Lovas, F. J.; Maki, A. G.; Olson, W. B. The Infrared Spectrum of $\mathrm{SiO}$ near $1240 \mathrm{~cm}^{-1}$ and Its Relation to the Circumstellar $\mathrm{SiO}$ Maser. J. Mol. Spectrosc. 1981, 87, 449-458.

(138) Tiemann, E.; Renwanz, E.; Hoeft, J.; Törring, T. Isotopieeffekte im Rotationsspektrum des $\mathrm{SiS} /$ lsotopic Effects in the Rotational Spectrum of SiS. Z. Naturforsch., A: Phys., Phys. Chem., Kosmophys. 1972, 27, 1566-1570.

(139) Hoeft, J.; Lovas, F. J.; Törring, T. Electrical Dipole Moments and Microwave Rotational Spectra of SiS. Z. Naturforsch., A: Astrophys., Phys. Phys. Chem. 1969, 24, 1422.

(140) Hoeft, J. Das Mikrowellenrotationsspektrum Des SiSe. Z. Naturforsch., A: Astrophys., Phys. Phys. Chem. 1965, 20, 1122.

(141) Hoeft, J.; Lovas, F. J.; Tiemann, E.; Törring, T. Dipole Moments and Hyperfine Structure of the Group-IV/VI Diatomic Molecules. J. Chem. Phys. 1970, 53, 2736.

(142) Törring, T. Das Mikrowellenrotationsspektrum Des SnO. Z. Naturforsch., A: Astrophys., Phys. Phys. Chem. 1967, 22, 1234.

(143) Murty, A. N.; Curl, R. F. Dipole Moments of the Sulfides of $\mathrm{Pb}, \mathrm{Sn}$, and Si from Stark Effect Measurements. J. Mol. Spectrosc. 1969, 30, 102-110.

(144) Hoeft, J. Das Mikrowellenrotationsspektrum Des SnSe. Z. Naturforsch., A: Astrophys., Phys. Phys. Chem. 1966, 21, 437.

(145) Hoeft, J.; Lovas, F. J.; Tiemann, E.; Tischer, R.; Törring, T. Elektrisches Dipolmoment und Mikrowellenrotationsspektrum des $\mathrm{GeO}$ und GeS. Z. Naturforsch., A: Astrophys., Phys. Phys. Chem. 1969, $24,1843$.

(146) Hoeft, J.; Tiemann, E. Das Mikrowellenrotationsspektrum des SnTe. Z. Naturforsch., A: Astrophys., Phys. Phys. Chem. 1968, 23, 1034.

(147) Fitzky, H. G. Das Mikrowellenrotationsspektrum Der Thallium I-Halogenide. Z. Phys. 1958, 151, 351-364.

(148) Tiemann, E. Elektrisches Dipolmoment von TlBr und TlJ. Z. Naturforsch., A: Phys., Phys. Chem., Kosmophys. 1971, 26, 1809.

(149) De Wijn, H. W. The Microwave Rotational Spectra of Thallium Mono-Chloride. Physica 1965, 31, 1193.

(150) Ley, R.; Schauer, W. Molekülstrahl-Resonanz-Messungen von Hyperfeinstruktur, Zeeman-und Stark-Effekt an TlCl-Isotopen in verschiedenen Schwingungszuständen/Molecular Beam Resonance
Measurements of Hyperfine Structure, Zeeman- and Stark-Effect of TICl-lsotopes in Different Vibrational States. Z. Naturforsch., A: Phys., Phys. Chem., Kosmophys. 1972, 27, 77.

(151) Dijkerman, H.; Monter, B.; Gräff, G.; Mönter, W. Beiträge zum Stark-Effekt der Moleküle ${ }^{205} \mathrm{~T} 1{ }^{19} \mathrm{~F}$ und ${ }^{39} \mathrm{~K}{ }^{19} \mathrm{~F} /$ Contributions to the Stark-Effect of the Molecules ${ }^{205} \mathrm{Tl}^{19} \mathrm{~F}$ and ${ }^{39} \mathrm{~K}^{19} \mathrm{~F}$. Z. Naturforsch., A: Phys., Phys. Chem., Kosmophys. 1972, 27, 100.

(152) v. Boeckh, R.; Gräff, G.; Ley, R. Die Abhängigkeit innerer und äußerer Wechselwirkungen des TlF-Moleküls von der Schwingung, Rotation und Isotopie. Z. Phys. 1964, 179, 285.

(153) Ryzlewicz, C.; Schütze-Pahlmann, H.-U.; Hoeft, J.; Törring, T. Rotational Spectrum and Hyperfine Structure of the ${ }^{2} \Sigma$ Radicals BaF and BaCl. Chem. Phys. 1982, 71, 389-399.

(154) Ryzlewicz, C.; Törring, T. Formation and Microwave Spectrum of the ${ }^{2} \Sigma$-Radical Barium-Monofluoride. Chem. Phys. 1980, 51, 329334

(155) Dixon, T. A.; Woods, R. C. The Laboratory Microwave Spectrum of the Cyanide Radical in Its $\mathrm{X}^{2} \Sigma^{+}$Ground State. J. Chem. Phys. 1977, 67, 3956-3964.

(156) Möller, K.; Schütze-Pahlmann, H. U.; Hoeft, J.; Törring, T. Effects of Unresolved Hyperfine Structure in the Microwave Rotational Spectra of the ${ }^{2} \Sigma$-Radicals $\mathrm{CaBr}$ and $\mathrm{CaCl}$. Chem. Phys. 1982, 68, 399-404.

(157) Schütze-Pahlmann, H.-U.; Ryzlewicz, C.; Hoeft, J.; Törring, T. Millimeter Wave Spectra of the ${ }^{2} \Sigma$ Radicals SrF and SrCl. Chem. Phys. Lett. 1982, 93, 74-77.

(158) Kuijpers, P.; Dymanus, A. Rotational Spectrum of BiBr. Chem. Phys. Lett. 1976, 39, 217-220.

(159) Kuijpers, P.; Törring, T.; Dymanus, A. Formation, Microwave Spectrum and Molecular Constants of Bismuth Monochloride. Chem. Phys. 1976, 18, 401-416.

(160) Kuijpers, P.; Dymanus, A. Millimeter Wave Spectrum of Gaseous Bismuth Monofluoride (BiF). Chem. Phys. 1977, 24, 97-103.

(161) Kuijpers, P.; Torring, T.; Dymanus, A. Microwave Spectrum of Bismuth Iodide (BiI). Chem. Phys. 1976, 12, 309-313.

(162) Bogey, M.; Demuynck, C.; Destombes, J. L. Millimeter Wave Spectrum of SO in Highly Excited Vibrational States: Vibrational and Isotopic Dependence of Molecular Constants. Chem. Phys. 1982, 66, 99-104.

(163) Parent, C. R.; Kuijpers, P. J. M. Millimeterwave Spectrum of $\mathrm{SeO}$ in the $\mathrm{X}^{3} \Sigma$-State. Chem. Phys. 1979, 40, 425-437.

(164) Millen, D. J.; Mitra, D. Microwave Spectrum, Structure and Nuclear Quadrupole Coupling Coefficients of Nitrosyl Bromide. Trans. Faraday Soc. 1970, 66, 2414.

(165) Lafferty, W. J.; Lide, D. R.; Toth, R. A. Infrared and Microwave Spectra of ClCN. J. Chem. Phys. 1965, 43, 2063.

(166) Millen, D. J.; Pannell, J. The Microwave Spectrum, Structure, and Nuclear Quadrupole Coupling Coefficients of Nitrosyl Chloride. J. Chem. Soc. 1961, 1322.

(167) Tyler, J. K.; Sheridan, J. Structural Studies of Linear Molecules by Microwave Spectroscopy. Trans. Faraday Soc. 1963, 59, 2661.

(168) Buckton, K. S.; Legon, A. C.; Millen, D. J. Microwave Spectrum and Structure of Nitrosyl Fluoride. Trans. Faraday Soc. 1969, 65, 1975.

(169) Takeo, H.; Curl, R. F. Microwave Spectrum of $\mathrm{GeF}_{2}$ : Quadrupole Coupling and Centrifugal Distortion. J. Mol. Spectrosc. 1972, 43, 21.

(170) Cook, R. L.; De Lucia, F. C.; Helminger, P. Molecular Force Field and Structure of Water: Recent Microwave Results. J. Mol. Spectrosc. 1974, 53, 62-76.

(171) Edwards, T. H.; Moncur, N. K.; Snyder, L. E. Ground-State Molecular Constants of Hydrogen Sulfide. J. Chem. Phys. 1967, 46, 2139.

(172) Cook, R. L.; De Lucia, F. C.; Helminger, P. Molecular Force Field and Structure of Hydrogen Sulfide: Recent Microwave Results. J. Mol. Struct. 1975, 28, 237-246.

(173) Oka, T.; Morino, Y. Analysis of the Microwave Spectrum of Hydrogen Selenide. J. Mol. Spectrosc. 1962, 8, 300. 
(174) Pearson, E. F.; McCormick, R. V. Rotational Spectrum and Structure of Thioborine: HBS. J. Chem. Phys. 1973, 58, 1619-1621.

(175) Winnewisser, G.; Maki, A. G.; Johnson, D. R. Rotational Constants for HCN and DCN. J. Mol. Spectrosc. 1971, 39, 149.

(176) Strey, G.; Mills, I. M. The Anharmonic Force Field and Equilibrium Structure of HCN and HCP. Mol. Phys. 1973, 26, 129138.

(177) Creswell, R. A.; Pearson, E. F.; Winnewisser, M.; Winnewisser, G. Detection of the Millimeter Wave Spectrum of Hydrogen Isocyanide, HNC. Z. Naturforsch., A: Phys., Phys. Chem., Kosmophys. 1976, 31, 221-224.

(178) Pearson, E. F.; Creswell, R. A.; Winnewisser, M.; Winnewisser, G. The Molecular Structures of HNC and HCN Derived from the Eight Stable Isotopic Species. Z. Naturforsch., A: Phys., Phys. Chem., Kosmophys. 1976, 31, 1394-1397.

(179) Costain, C. C. Determination of Molecular Structures from Ground State Rotational Constants. J. Chem. Phys. 1958, 29, 864-874.

(180) Beppu, T.; Hirota, E.; Morino, Y. Microwave Spectrum, Structure, Quadrupole Coupling Constant, and Force Constants of NSCl. J. Mol. Spectrosc. 1970, 36, 386.

(181) Tanaka, T.; Morino, Y. Coriolis Interaction and Anharmonic Potential Function of Ozone from the Microwave Spectra in Excited Vibrational States. J. Mol. Spectrosc. 1970, 33, 538.

(182) Maki, A. G.; Johnson, D. R. Microwave Spectra of Carbonyl Sulfide: Measurements of Ground State and Vibrationally Excited ${ }^{16} \mathrm{O}^{13} \mathrm{C}^{32} \mathrm{~S},{ }^{18} \mathrm{O}^{12} \mathrm{C}^{32} \mathrm{~S}$, and Other Isotopic Species. J. Mol. Spectrosc. 1973, 47, 226-233.

(183) Maki, A. G.; Sams, R. L.; Pearson, R. Microwave and Infrared Spectra of Isotopically Substituted Carbonyl Selenide (OCSe). J. Mol. Spectrosc. 1977, 64, 452-459.

(184) Morino, Y.; Saito, S. Microwave Spectrum of Oxygen Difluoride in Vibrationally Excited States; $\nu_{1}-2 \nu_{2}$ Fermi Resonance and Equilibrium Structure. J. Mol. Spectrosc. 1966, 19, 435.

(185) Saito, S. Microwave Spectrum of Sulfur Dioxide in Doubly Excited Vibrational States and Determination of $\gamma$ Constants. J. Mol. Spectrosc. 1969, 30, 1.

(186) Takeo, H.; Hirota, E.; Morino, Y. Equilibrium Structure and Potential Function of Selenium Dioxide by Microwave Spectroscopy. J. Mol. Spectrosc. 1970, 34, 370.

(187) Shoji, H.; Tanaka, T.; Hirota, E. Microwave-Spectrum of Silicon Difluoride in the Excited Vibrational States, Equilibrium Structure, Anharmonic Potential Function, and $\nu 1-\nu 3$ Coriolis Resonance. J. Mol. Spectrosc. 1973, 47, 268-274.

(188) Tolles, W. M.; Kinsey, J. L.; Curl, R. F.; Heidelberg, R. F. Microwave Spectrum of Chlorine Dioxide. V. The Stark and Zeeman Effects. J. Chem. Phys. 1962, 37, 927.

(189) Curl, R. F.; Heidelberg, R. F.; Kinsey, J. L. Microwave Spectrum of Chlorine Dioxide. II. Analysis of Hyperfine Structure and the Spectrum of $\mathrm{Cl}_{35} \mathrm{O}_{16} \mathrm{O}_{18}$. Phys. Rev. 1962, 125, 1993.

(190) Tolles, W. M.; Curl, R. F.; Heidelberg, R. F. The Stark and Zeeman Effect of $\mathrm{ClO}_{2}$. Spectrochim. Acta 1962, 18, 1368.

(191) Cabana, A.; Laurin, M.; Lafferty, W. J.; Sams, R. L. High Resolution Infrared Spectra of $\nu_{2}$ and $2 \nu_{1}$ Bands of ${ }^{14} \mathrm{~N}^{16} \mathrm{O}_{2}$. Can. J. Phys. 1975, 53, 1902-1926.

(192) Frisch, M. J.; Trucks, G. W.; Schlegel, H. B.; Scuseria, G. E.; Robb, M. A.; Cheeseman, J. R.; Scalmani, G.; Barone, V.; Mennucci, B.; Petersson, G. A.; Nakatsuji, H.; Caricato, M.; Li, X.; Hratchian, H. P.; Izmaylov, A. F.; Bloino, J.; Zheng, G.; Sonnenberg, J. L.; Hada, M.; Ehara, M.; Toyota, K.; Fukuda, R.; Hasegawa, J.; Ishida, M.; Nakajima, T.; Honda, Y.; Kitao, O.; Nakai, H.; Vreven, T.; Montgomery, J. A., Jr.; Peralta, J. E.; Ogliaro, F.; Bearpark, M. J.; Heyd, J.; Brothers, E. N.; Kudin, K. N.; Staroverov, V. N.; Kobayashi, R.; Normand, J.; Raghavachari, K.; Rendell, A. P.; Burant, J. C.; Iyengar, S. S.; Tomasi, J.; Cossi, M.; Rega, N.; Millam, N. J.; Klene, M.; Knox, J. E.; Cross, J. B.; Bakken, V.; Adamo, C.; Jaramillo, J.; Gomperts, R.; Stratmann, R. E.; Yazyev, O.; Austin, A. J.; Cammi, R.; Pomelli, C.; Ochterski, J. W.; Martin, R. L.; Morokuma, K.; Zakrzewski, V. G.; Voth, G. A.; Salvador, P.; Dannenberg, J. J.; Dapprich, S.; Daniels, A.
D.; Farkas, Ö.; Foresman, J. B.; Ortiz, J. V.; Cioslowski, J.; Fox, D. J. Gaussian 09; Gaussian, Inc.: Wallingford, CT, USA, 2009.

(193) Grimme, S.; Antony, J.; Ehrlich, S.; Krieg, H. A Consistent and Accurate $\mathrm{Ab}$ Initio Parametrization of Density Functional Dispersion Correction (DFT-D) for the 94 Elements H-Pu. J. Chem. Phys. 2010, 132, 154104.

(194) Minenkov, Y.; Bistoni, G.; Riplinger, C.; Auer, A. A.; Neese, F.; Cavallo, L. Pair Natural Orbital and Canonical Coupled Cluster Reaction Enthalpies Involving Light to Heavy Alkali and Alkaline Earth Metals: The Importance of Sub-Valence Correlation. Phys. Chem. Chem. Phys. 2017, 19, 9374-9391.

(195) Bauschlicher, C. W.; Melius, C. F.; Allendorf, M. D. Gallium Compounds, a Possible Problem for the G2 Approaches. J. Chem. Phys. 1999, 110, 1879-1881.

(196) Austin, A. J.; Frisch, M. J.; Montgomery, J. A.; Petersson, G. A. An Overlap Criterion for Selection of Core Orbitals. Theor. Chem. Acc. 2002, 107, 180-186.

(197) Schulz, A.; Smith, B. J.; Radom, L. Heats of Formation of Alkali and Alkaline Earth Oxides and Hydroxides: Some Dramatic Failures of the G2 Method. J. Phys. Chem. A 1999, 103, 7522-7527.

(198) Sullivan, M. B.; Iron, M. A.; Redfern, P. C.; Martin, J. M. L.; Curtiss, L. A.; Radom, L. Heats of Formation of Alkali Metal and Alkaline Earth Metal Oxides and Hydroxides: Surprisingly Demanding Targets for High-Level Ab Initio Procedures. J. Phys. Chem. A 2003, $107,5617-5630$.

(199) Iron, M. A.; Oren, M.; Martin, J. M. L. Alkali and Alkaline Earth Metal Compounds: Core-Valence Basis Sets and Importance of Subvalence Correlation. Mol. Phys. 2003, 101, 1345-1361.

(200) Gong, Y.; Andrews, L.; Bauschlicher, C. W.; Thanthiriwatte, K. S.; Dixon, D. A. Infrared Spectroscopic and Theoretical Studies of the $\mathrm{OTiF}_{2}, \mathrm{OZrF}_{2}$ and $\mathrm{OHfF}_{2}$ Molecules with Terminal Oxo Ligands. Dalton Trans. 2012, 41, 11706-11715.

(201) Dunning, T. H. Gaussian Basis Sets for Use in Correlated Molecular Calculations. I. The Atoms Boron through Neon and Hydrogen. J. Chem. Phys. 1989, 90, 1007-1023.

(202) Prascher, B. P.; Woon, D. E.; Peterson, K. A.; Dunning, T. H., Jr.; Wilson, A. K. Gaussian Basis Sets for Use in Correlated Molecular Calculations. VII. Valence, Core-Valence, and Scalar Relativistic Basis Sets for Li, Be, Na, and Mg. Theor. Chem. Acc. 2011, 128, 69-82.

(203) Peterson, K. A.; Dunning, T. H. Accurate Correlation Consistent Basis Sets for Molecular Core-Valence Correlation Effects: The Second Row Atoms Al-Ar, and the First Row Atoms B-Ne Revisited. J. Chem. Phys. 2002, 117, 10548-10560.

(204) Li, H.; Feng, H.; Sun, W.; Zhang, Y.; Fan, Q.; Peterson, K. A.; Xie, Y.; Schaefer, H. F., III The Alkaline Earth Dimer Cations $\left(\mathrm{Be}_{2}^{+}\right.$, $\mathrm{Mg}^{2+}, \mathrm{Ca}_{2}^{+}, \mathrm{Sr}_{2}^{+}$, and $\left.\mathrm{Ba}_{2}^{+}\right)$. Coupled Cluster and Full Configuration Interaction Studies. Mol. Phys. 2013, 111, 2292-2298.

(205) Lim, I. S.; Stoll, H.; Schwerdtfeger, P. Relativistic Small-Core Energy-Consistent Pseudopotentials for the Alkaline-Earth Elements from Ca to Ra. J. Chem. Phys. 2006, 124, 034107.

(206) Peterson, K. A.; Puzzarini, C. Systematically Convergent Basis Sets for Transition Metals. II. Pseudopotential-Based Correlation Consistent Basis Sets for the Group $11(\mathrm{Cu}, \mathrm{Ag}, \mathrm{Au})$ and $12(\mathrm{Zn}, \mathrm{Cd}$, $\mathrm{Hg}$ ) Elements. Theor. Chem. Acc. 2005, 114, 283-296.

(207) Figgen, D.; Rauhut, G.; Dolg, M.; Stoll, H. Energy-Consistent Pseudopotentials for Group 11 and 12 Atoms: Adjustment to MultiConfiguration Dirac-Hartree-Fock Data. Chem. Phys. 2005, 311, 227-244.

(208) Peterson, K. A.; Yousaf, K. E. Molecular Core-Valence Correlation Effects Involving the Post-d Elements Ga-Rn: Benchmarks and New Pseudopotential-Based Correlation Consistent Basis Sets. J. Chem. Phys. 2010, 133, 174116.

(209) Metz, B.; Stoll, H.; Dolg, M. Small-Core MulticonfigurationDirac-Hartree-Fock-Adjusted Pseudopotentials for Post-d Main Group Elements: Application to $\mathrm{PbH}$ and PbO. J. Chem. Phys. 2000, $113,2563-2569$.

(210) Peterson, K. A.; Figgen, D.; Goll, E.; Stoll, H.; Dolg, M. Systematically Convergent Basis Sets with Relativistic Pseudopotentials. II. Small-Core Pseudopotentials and Correlation Consistent Basis 
Sets for the Post-d Group 16-18 Elements. J. Chem. Phys. 2003, 119, $11113-11123$

(211) Metz, B.; Schweizer, M.; Stoll, H.; Dolg, M.; Liu, W. A SmallCore Multiconfiguration Dirac-Hartree-Fock-Adjusted Pseudopotential for Tl-Application to Tl X (X= F, Cl, Br, I). Theor. Chem. Acc. 2000, 104, 22-28.

(212) Perdew, J. P. Density-Functional Approximation for the Correlation Energy of the Inhomogeneous Electron Gas. Phys. Rev. B 1986, 33, 8822-8824.

(213) Hamprecht, F. A.; Cohen, A. J.; Tozer, D. J.; Handy, N. C. Development and Assessment of New Exchange-Correlation Functionals. J. Chem. Phys. 1998, 109, 6264-6271.

(214) Boese, A. D.; Doltsinis, N. L.; Handy, N. C.; Sprik, M. New Generalized Gradient Approximation Functionals. J. Chem. Phys. 2000, 112, 1670-1678.

(215) Boese, A. D.; Handy, N. C. A New Parametrization of Exchange-Correlation Generalized Gradient Approximation Functionals. J. Chem. Phys. 2001, 114, 5497-5503.

(216) Grimme, S. Semiempirical GGA-type Density Functional Constructed with a Long-Range Dispersion Correction. J. Comput. Chem. 2006, 27, 1787-1799.

(217) Grimme, S.; Ehrlich, S.; Goerigk, L. Effect of the Damping Function in Dispersion Corrected Density Functional Theory. J. Comput. Chem. 2011, 32, 1456-1465.

(218) Peverati, R.; Zhao, Y.; Truhlar, D. G. Generalized Gradient Approximation That Recovers the Second-Order Density-Gradient Expansion with Optimized across-the-Board Performance. J. Phys. Chem. Lett. 2011, 2, 1991-1997.

(219) Peverati, R.; Truhlar, D. G. Exchange-Correlation Functional with Good Accuracy for Both Structural and Energetic Properties While Depending Only on the Density and Its Gradient. J. Chem. Theory Comput. 2012, 8, 2310-2319.

(220) Handy, N. C.; Cohen, A. J. Left-Right Correlation Energy. Mol. Phys. 2001, 99, 403-412.

(221) Hoe, W.-M.; Cohen, A. J.; Handy, N. C. Assessment of a New Local Exchange Functional OPTX. Chem. Phys. Lett. 2001, 341, 319328.

(222) Miehlich, B.; Savin, A.; Stoll, H.; Preuss, H. Results Obtained with the Correlation Energy Density Functionals of Becke and Lee, Yang and Parr. Chem. Phys. Lett. 1989, 157, 200-206.

(223) Tao, J.; Perdew, J. P.; Staroverov, V. N.; Scuseria, G. E. Climbing the Density Functional Ladder: Nonempirical MetaGeneralized Gradient Approximation Designed for Molecules and Solids. Phys. Rev. Lett. 2003, 91, 146401.

(224) Van Voorhis, T.; Scuseria, G. E. A Novel Form for the Exchange-Correlation Energy Functional. J. Chem. Phys. 1998, 109, 400-410.

(225) Zhao, Y.; Truhlar, D. G. A New Local Density Functional for Main-Group Thermochemistry, Transition Metal Bonding, Thermochemical Kinetics, and Noncovalent Interactions. J. Chem. Phys. 2006, 125, 194101.

(226) Peverati, R.; Truhlar, D. G. M11-L: A Local Density Functional That Provides Improved Accuracy for Electronic Structure Calculations in Chemistry and Physics. J. Phys. Chem. Lett. 2012, 3, 117124.

(227) Peverati, R.; Truhlar, D. G. An Improved and Broadly Accurate Local Approximation to the Exchange-Correlation Density Functional: The MN12-L Functional for Electronic Structure Calculations in Chemistry and Physics. Phys. Chem. Chem. Phys. 2012, 14, 1317113174.

(228) Ziesche, P.; Eschrig, H. Electronic Structure of Solids '91: Proceedings of the 75 WE-Heraeus-Seminar and 21st Annual International Symposium on Electronic Structure of Solids, 1st ed.; Akademie Verlag: Berlin, 1991; pp 1-249.

(229) Perdew, J. P.; Chevary, J. A.; Vosko, S. H.; Jackson, K. A.; Pederson, M. R.; Singh, D. J.; Fiolhais, C. Atoms, Molecules, Solids, and Surfaces: Applications of the Generalized Gradient Approximation for Exchange and Correlation. Phys. Rev. B 1992, 46, 6671-6687.
(230) Perdew, J. P.; Chevary, J. A.; Vosko, S. H.; Jackson, K. A.; Pederson, M. R.; Singh, D. J.; Fiolhais, C. Erratum: Atoms, Molecules, Solids, and Surfaces: Applications of the Generalized Gradient Approximation for Exchange and Correlation. Phys. Rev. B 1993, 48, 4978.

(231) Perdew, J. P.; Burke, K.; Wang, Y. Generalized Gradient Approximation for the Exchange-Correlation Hole of a Many-Electron System. Phys. Rev. B 1996, 54, 16533-16539.

(232) Dobson, J. F.; Vignale, G.; Das, M. P. Electronic Density Functional Theory: Recent Progress and New Directions; Springer: Heidelberg, 1988; pp 1-396.

(233) Adamo, C.; Barone, V. Exchange Functionals with Improved Long-Range Behavior and Adiabatic Connection Methods without Adjustable Parameters: The MPW and MPW1PW Models. J. Chem. Phys. 1998, 108, 664-675.

(234) Peverati, R.; Truhlar, D. G. Communication: A Global Hybrid Generalized Gradient Approximation to the Exchange-Correlation Functional That Satisfies the Second-Order Density-Gradient Constraint and Has Broad Applicability in Chemistry. J. Chem. Phys. 2011, 135, 191102.

(235) Xu, X.; Goddard, W. A. The X3LYP Extended Density Functional for Accurate Descriptions of Nonbond Interactions, Spin States, and Thermochemical Properties. Proc. Natl. Acad. Sci. U.S.A. 2004, 101, 2673-2677.

(236) Wilson, P. J.; Bradley, T. J.; Tozer, D. J. Hybrid ExchangeCorrelation Functional Determined from Thermochemical Data and Ab Initio Potentials. J. Chem. Phys. 2001, 115, 9233-9242.

(237) Becke, A. D. Density-Functional Thermochemistry. V. Systematic Optimization of Exchange-Correlation Functionals. J. Chem. Phys. 1997, 107, 8554-8560.

(238) Schmider, H. L.; Becke, A. D. Optimized Density Functionals from the Extended G2 Test Set. J. Chem. Phys. 1998, 108, 9624-9631.

(239) Adamo, C.; Barone, V. Toward Reliable Adiabatic Connection Models Free from Adjustable Parameters. Chem. Phys. Lett. 1997, 274, 242-250.

(240) Austin, A.; Petersson, G. A.; Frisch, M. J.; Dobek, F. J.; Scalmani, G.; Throssell, K. A Density Functional with Spherical Atom Dispersion Terms. J. Chem. Theory Comput. 2012, 8, 4989-5007.

(241) Vydrov, O. A.; Scuseria, G. E. Assessment of a Long-Range Corrected Hybrid Functional. J. Chem. Phys. 2006, 125, 234109.

(242) Yanai, T.; Tew, D. P.; Handy, N. C. A New Hybrid ExchangeCorrelation Functional Using the Coulomb-Attenuating Method (CAM-B3LYP). Chem. Phys. Lett. 2004, 393, 51-57.

(243) Peverati, R; Truhlar, D. G. Screened-Exchange Density Functionals with Broad Accuracy for Chemistry and Solid-State Physics. Phys. Chem. Chem. Phys. 2012, 14, 16187-16191.

(244) Chai, J.-D.; Head-Gordon, M. Long-Range Corrected Hybrid Density Functionals with Damped Atom-Atom Dispersion Corrections. Phys. Chem. Chem. Phys. 2008, 10, 6615-6620.

(245) Boese, A. D.; Martin, J. M. L. Development of Density Functionals for Thermochemical Kinetics. J. Chem. Phys. 2004, 121, $3405-3416$

(246) Staroverov, V. N.; Scuseria, G. E.; Tao, J. M.; Perdew, J. P. Comparative Assessment of a New Nonempirical Density Functional: Molecules and Hydrogen-Bonded Complexes. J. Chem. Phys. 2003, 119, 12129-12137.

(247) Zhao, Y.; Truhlar, D. G. The M06 Suite of Density Functionals for Main Group Thermochemistry, Thermochemical Kinetics, Noncovalent Interactions, Excited States, and Transition Elements: Two New Functionals and Systematic Testing of Four M06-Class Functionals and 12 Other Functionals. Theor. Chem. Acc. 2008, 120, 215-241.

(248) Peverati, R.; Truhlar, D. G. Improving the Accuracy of Hybrid Meta-GGA Density Functionals by Range Separation. J. Phys. Chem. Lett. 2011, 2, 2810-2817.

(249) Møller, C.; Plesset, M. S. Note on an Approximation Treatment for Many-Electron Systems. Phys. Rev. 1934, 46, 618-622.

(250) Ćížek, J. On the Use of the Cluster Expansion and the Technique of Diagrams in Calculations of Correlation Effects in 
Atoms and Molecules. In Advances in Chemical Physics; LeFebvre, R., Moser, C., Eds.; John Wiley \& Sons, Inc.: Hoboken, NJ, USA, 2007; Vol. 14, pp 35-89.

(251) Purvis, G. D.; Bartlett, R. J. A Full Coupled-Cluster Singles and Doubles Model: the Inclusion of Disconnected Triples. J. Chem. Phys. 1982, 76, 1910-1918.

(252) Scuseria, G. E.; Janssen, C. L.; Schaefer, H. F. An Efficient Reformulation of the Closed-Shell Coupled Cluster Single and Double Excitation (CCSD) Equations. J. Chem. Phys. 1988, 89, 7382-7387.

(253) Scuseria, G. E.; Schaefer, H. F. Is Coupled Cluster Singles and Doubles (CCSD) More Computationally Intensive Than Quadratic Configuration Interaction (QCISD)? J. Chem. Phys. 1989, 90, 37003703.

(254) McCullough, E. A.; Aprà, E.; Nichols, J. Comparison of the Becke-Lee-Yang-Parr and Becke-Perdew-Wang Exchange-Correlation Functionals for Geometrics of Cyclopentadienyl-Transition Metal Complexes. J. Phys. Chem. A 1997, 101, 2502-2508.

(255) Johnson, B. G.; Gill, P. M. W.; Pople, J. A. The Performance of a Family of Density Functional Methods. J. Chem. Phys. 1993, 98, $5612-5626$.

(256) Braïda, B.; Hiberty, P. C.; Savin, A. A Systematic Failing of Current Density Functionals: Overestimation of Two-Center ThreeElectron Bonding Energies. J. Phys. Chem. A 1998, 102, 7872-7877.

(257) Koch, W.; Holthausen, M. C.; Baerends, E. J. A Chemist's Guide to Density Functional Theory; Wiley-VCH Verlag GmbH: Weinheim, 2001; pp 1-294.

(258) Bistoni, G.; Riplinger, C.; Minenkov, Y.; Cavallo, L.; Auer, A. A.; Neese, F. Treating Subvalence Correlation Effects in Domain Based Pair Natural Orbital Coupled Cluster Calculations: An out-ofthe-Box Approach. J. Chem. Theory Comput. 2017, 13, 3220-3227.

(259) Wang, Z.; Wang, F. Analysis of a Failure of the CC2 CoupledCluster Method for Bond Lengths of $\mathrm{SnO}$ and $\mathrm{PbO}$. Theor. Chem. Acc. 2014, 133, 1579-1586.

(260) Wang, F.; Gauss, J. Analytic Energy Gradients in Closed-Shell Coupled-Cluster Theory with Spin-Orbit Coupling. J. Chem. Phys. 2008, 129, 174110.

(261) Wang, F.; Gauss, J. Analytic Second Derivatives in Closed-Shell Coupled-Cluster Theory with Spin-Orbit Coupling. J. Chem. Phys. 2009, 131, 164113.

(262) Wang, F.; Gauss, J.; van Wüllen, C. Closed-Shell CoupledCluster Theory with Spin-Orbit Coupling. J. Chem. Phys. 2008, 129, 064113.

(263) Gao, D.-D.; Cao, Z.; Wang, F. Spin-Orbit Effects in ClosedShell Heavy and Superheavy Element Monohydrides and Monofluorides with Coupled-Cluster Theory. J. Phys. Chem. A 2016, 120, $1231-1242$.

(264) Tu, Z.; Yang, D.-D.; Wang, F.; Guo, J. Symmetry Exploitation in Closed-Shell Coupled-Cluster Theory with Spin-Orbit Coupling. J. Chem. Phys. 2011, 135, 034115.

(265) Liu, W.; van Wüllen, C. Spectroscopic Constants of Gold and Eka-Gold (Element 111) Diatomic Compounds: The Importance of Spin-Orbit Coupling. J. Chem. Phys. 1999, 110, 3730-3735.

(266) Han, Y.-K.; Bae, C.; Son, S.-K.; Lee, Y. S. Spin-Orbit Effects on the Transactinide p-Block Element Monohydrides MH (M=Element 113-118). J. Chem. Phys. 2000, 112, 2684-2691.

(267) Cao, Z.; Wang, F.; Yang, M. Coupled-Cluster Method for Open-Shell Heavy-Element Systems with Spin-Orbit Coupling. J. Chem. Phys. 2017, 146, 134108.

(268) Taylor, P. "Accurate Calculations and Calibration" in Lecture Notes in Quantum Chemistry; Roos, B. O., Ed.; Springer-Verlag, 1992. (269) Johnson, E. R.; Mackie, I. D.; DiLabio, G. A. Dispersion Interactions in Density-Functional Theory. J. Phys. Org. Chem. 2009, 22, 1127-1135.

(270) Johnson, E. R.; Becke, A. D.; Sherrill, C. D.; DiLabio, G. A. Oscillations in Meta-Generalized-Gradient Approximation Potential Energy Surfaces for Dispersion-Bound Complexes. J. Chem. Phys. 2009, 131, 034111.
(271) Occhipinti, G.; Bjørsvik, H.-R.; Jensen, V. R. Quantitative Structure-Activity Relationships of Ruthenium Catalysts for Olefin Metathesis. J. Am. Chem. Soc. 2006, 128, 6952-6964. 